\title{
Progress in Clinical Neurosciences: Canadian Guidelines for the Development of Antidementia Therapies: A Conceptual Summary
}

\author{
Howard H. Feldman, Serge Gauthier, Howard Chertkow, David K. Conn, Morris \\ Freedman, Chris MacKnight for the 2nd Canadian Conference on Antidementia \\ Guidelines (A detailed list of contributors is located at the end of this document)
}

\begin{abstract}
The magnitude of the problems faced by an aging Canadian society has been clearly identified. Perhaps the single most important problem is the increasing incidence of dementia. Alzheimer's disease (AD) accounts for 50-60\% of the dementias in later life within a spectrum of other contributing dementias. Regulatory approval has been given to Acetylcholinesterase inhibitors for the symptomatic treatment of mild to moderate $\mathrm{AD}$, and conditional approval to memantine for the symptoms of moderate to severe $\mathrm{AD}$. There has been no regulatory approval for the treatment of the degenerative dementias beyond AD. The very rapid progress in the past decade in biotechnology and in the molecular biology of the dementias is supporting a new generation of innovative treatment strategies that will more directly target the underlying disease pathogenic mechanisms. Such treatments will foreseeably include immunotherapies, anti-aggregants that may prevent misfolding and deposition of proteins, and neuroregenerative interventions. These Guidelines follow the 2nd Canadian Conference on the Development of Antidementia Therapies, held in 2004, which covered a range of design, methodological and ethical issues facing clinical researchers and regulatory authorities. They are intended to provide a common point of reference and guidance in Canada for therapeutic development of the dementias.
\end{abstract}

RÉSUMÉ: Lignes directrices canadiennes pour le développement de traitements de la démence: sommaire conceptuel. L'amplitude du problème auquel fait face la société canadienne vieillissante a été clairement identifiée. Le problème le plus important est l'incidence croissante de la démence. De 50 à $60 \%$ des cas de démence chez les gens âgés sont dus à la maladie d'Alzheimer (MA). Des inhibiteurs de l'acétylcholinestérase ont été approuvés pour le traitement symptomatique de la MA légère ou modérée et la mémantine a reçu une approbation conditionnelle pour le traitement des symptômes modérés ou sévères de la MA. Aucun traitement des démences dégénératives autres que la MA n’a été approuvé. Les progrès très rapides de la recherche sur les démences en biotechnologie et en biologie moléculaire pendant la dernière décennie sont à l'origine d'une nouvelle génération de stratégies novatrices de traitement qui cibleront plus directement les mécanismes pathogéniques de la maladie sous-jacente. Il est probable que différentes stratégies seront utilisées dont l'immunothérapie, les anti-agrégants qui préviennent le pliage erroné de protéines et leur dépôt et les interventions neurorégénératrices. Ces lignes directrices sont émises suite à la deuxième conférence canadienne sur le développement de traitements anti-démence en 2004. Cette conférence a examiné plusieurs questions de modèles, de méthodologies et d'éthique auxquels sont confrontés les cliniciens chercheurs et les organismes réglementaires. Elles offrent un point de référence commun et une orientation pour le développement de traitements des démences au Canada.

Can. J. Neurol. Sci. 2006; 33: 6-26

Dementias are now recognized to present some of the most important challenges to face medicine in the 21 st century. The Canadian Study of Health and Aging (CSHA) reported that, in 1991, the prevalence figures for all types of dementia were $80 / 1,000$ in those over the age of 65 and 345/1,000 in those over the age of 85 in this country. The study projected that by 2011 there would be 475,000 individuals over the age of 65 affected with dementia. ${ }^{1}$ Of those affected with dementia, $50-65 \%$ have a diagnosis of Alzheimer's Disease (AD), while mixed causes of dementia are increasingly recognized. The direct and indirect cost of care for each patient with $\mathrm{AD}$ has been estimated to vary between $\$ 16,000$ to as much as $\$ 37,000$ per year (1998, CAD), with increasing costs tied to disease severity. ${ }^{2}$ This estimate
From the Division of Neurology, Department of Medicine, University of British Columbia (HHF), Clinic for Alzheimer's Disease and Related Disorders, Vancouver Coastal Health, Vancouver, BC; Departments of Psychiatry, Neurology \& Neurosurgery, Medicine, Faculty of Medicine, McGill University (SG), Alzheimer Disease \& Related Disorders Unit, McGill Center for studies in Aging, Montreal, QC; Department of Neurology and Neurosurgery, McGill University (HC), Memory Clinic, Department of Neurology, Sir Mortimer B. Davis, Jewish General Hospital, Montreal, QC; Department of Psychiatry, University of Toronto (DKC), Department of Psychiatry, Baycrest Centre for Geriatric Care, Toronto, ON; Department of Medicine, Division of Neurology, Mount Sinai Hospital (MF), University Health Network and University of Toronto; Behavioural Neurology Program and Rotman Research Institute, Baycrest Centre For Geriatric Care, Toronto, ON; Department of Medicine, Dalhousie University (CM), Centre for Health Care of the Elderly, Capital District Health Authority, Halifax, Nova Scotia.

Received MAy 3, 2005. AcCePted In FinAl fORM SEPTEMber 10, 2005. Reprint requests to: Howard H. Feldman, Division of Neurology, University of British Columbia, S192-2211 Wesbrook Mall, Vancouver, British Columbia, V6T 2B5, Canada. 
means that billions of dollars are spent on the care of AD patients at the present time in Canada. To meet this challenge, both government and the private sector will need to make major investments in research on the prevention of dementia, its treatments and on the community infrastructure needed to manage these illnesses.

Major advances in both molecular neurobiology and biotechnology hold considerable promise in translating basic neuroscientific findings into more definitive therapies aimed at treating the pathologies of the dementias. This rapid growth of research, however, requires careful consideration of the range of ethical issues that come up almost continually. As well, the development of new treatment approaches for dementia will require position papers to be published and disseminated to stimulate the public discussion needed on these very important issues related to antidementia treatments. The existence of an integrated network of investigators from within the Consortium of Canadian Centres for Clinical Cognitive Research (C5R), the Canadian Neurological Society, the Canadian Academy of Geriatric Psychiatry (CAGP), and the Canadian Geriatrics Society (CGS), allow Canada to play a significant role in addressing this important global problem.

The goal of this Guidelines paper is to provide a broad conceptual summary that can serve as a point of common reference to clinicians, clinical researchers, government agencies, and the pharmaceutical, biotechnology industries in Canada who all face the important challenge of the dementias together in the coming decades. It is presented in a similar form of draft statements and recommendations to the Guidelines for Antidementia Therapies that were published in this journal in $1995 .^{3}$

\section{Methods}

The 2nd Canadian Conference on Antidementia Drug Guidelines was convened October 28-29, 2004, in Montreal. The conveners of the conference (H. Feldman and S. Gauthier) established a steering committee with the chairs of each of the major Canadian medical societies involved in the care of patients with dementia, including H. Chertkow (C5R), D. Conn (CAGP), C. MacKnight (CGS), and M. Freedman (Canadian Neurological Society). An agenda was developed to cover the range of diagnostic and treatment standards, study designs, ethical issues related to the development of therapies, outcome measures, biological markers, and the broad spectrum of the dementias. Emphasis was placed on both the current state of the art as well as on the anticipated future issues around each topic. Each participating organization was asked to recommend five representatives with recognized expertise for each topic area, to ensure the highest level of contribution to the conference. Selected consultants were then added to the conference to cover specialized areas outside of the expertise of the working group, including D. Streiner who spoke on design and methodologic issues, and J. Poirier who provided a future vision of the development of therapies. Important regulatory guidance was provided by three participating members of the Central Nervous System (CNS) Division of the Therapeutic Products Directorate (TPD) of Health Canada. The Alzheimer Society of Canada sent three representatives to the Conference to ensure that the perspective of patients and caregivers was fully considered. Finally, there were a number of international external consultants invited, including the Chair of the International Working Group on the Harmonization of Antidementia Drug Guidelines (Dr. J.M. Orgogozo), and a member of the United States Food and Drug Administration Advisory Panel on Dementia (Dr. S. DeKosky).

In preparation for the conference, all of the medical society representatives were asked to submit a 500-word summary statement and potential recommendations for their assigned topic. Participants working within specific topic areas met with the conveners via teleconference to review their progress and discuss their perspectives before the conference. Each participant was also asked to submit a more expanded 2,000-word background paper to capture the basis of their summary statements and recommendations. At the time of the conference each topic was presented in a short plenary format, followed by an open-session discussion of the recommendations that had been proposed. The summary of the conference and its recommendations were finalized and prepared for publication by the authors of this paper.

During the conference, all participants provided statements of disclosure of their involvement with pharmaceutical and biotechnology companies, which are held on file. Funding for the conference was received through a workshop grant of the Canadian Institutes of Health Research (CIHR) Institute on Aging and through grants-in-aid to the meeting from a large number of pharmaceutical companies who were invited in an observer role (see Acknowledgements for details). All meeting funding was received and administered by MedPlan who was responsible for the logistics and organization of the meeting.

\section{Diagnostic Criteria and Approaches for Research STUDIES}

\section{Dementia}

The syndrome of dementia consists of cognitive and functional decline and is frequently associated with behavioural symptoms and personality changes. ${ }^{4}$ For the effective evaluation of treatment strategies, a consistent diagnostic framework must be adhered to. While a number of diagnostic criteria have been proposed worldwide, in Canada, the Diagnostic and Statistical Manual of Mental Disorders, Fourth Edition, Text Revision (DSM-IV-TR) is the most widely used framework for the general definition of dementia. ${ }^{5}$ This diagnostic standard continues to be revised and will be updated.

There are some noted deficiencies in the DSM-IV-TR criteria. Of particular concern is the central emphasis on the memory domain, whereas some forms of dementia frequently present without a prominent memory deficit. The provision that there be a progressive decline in any two cognitive domains, each resulting in impairment in social or occupational function, would allow a broader range of dementias to be captured beyond those that can be identified by the DSM-IV-TR. Furthermore, there is no requirement for neuroimaging within the diagnostic research criteria, yet it is standard that neuroimaging be performed in all subjects participating in dementia therapeutic trials. This is viewed as an essential part of determining vascular elements 
within dementia and should be included in proposed criteria to allow the highest degree of diagnostic accuracy and characterization of persons entering into therapeutic trials.

\section{Alzheimer's Disease}

The DSM IV-TR and National Institute of Neurological and Communicative Disorders and Stroke-Alzheimer's Disease and Related Disorders Association (NINCDS-ADRDA) criteria for AD provide the clinical diagnostic standards for research studies. $^{4,5}$ These criteria have been validated both clinically and pathologically. While their diagnostic sensitivity has ranged from very good to excellent, their specificity has been problematic in many studies, ${ }^{6-8}$ and their inter-rater reliability has ranged from only fair to very good. ${ }^{7}$ There are inherent limitations in measuring the accuracy of diagnostic criteria where the gold standard neuropathology that is most widely used is based on a probabilistic likelihood and where more than one pathological process may contribute to dementia. ${ }^{9}$ Within the NINCDS-ADRDA criteria, the distinction between "possible" and "probable" AD has been difficult to apply particularly in the presence of multiple comorbid pathologies. It is now recognized that cerebrovascular dementia and AD co-exist clinically at a frequency in $30-40 \%$ of all dementia cases. ${ }^{10,11}$ Other subgroups within possible AD have also been identified. "Possible AD" has been generally removed from AD clinical trials research focus and the licensing of $\mathrm{AD}$ treatment for "probable" $\mathrm{AD}$ leaves a significant percentage of patients with mixed disorders being treated off of labeled indication and without sufficient supportive data on efficacy and safety. The deficiencies of the NINCDS-ADRDA criteria in addressing comorbid and mixed $\mathrm{AD}$ pathologies need to be addressed in future $\mathrm{AD}$ diagnostic criteria, as will the need to include study groups with mixed pathologies within the clinical trial development of therapies.

With the emergence of naturalistic and treatment studies focusing on earlier $\mathrm{AD}$ identification beginning with the stage of mild cognitive impairment (MCI), there is also a current need to develop more sensitive formal diagnostic criteria for early disease. These criteria will need to be shown to reliably identify disease in patients who do not meet current standard criteria. Criteria for earlier AD diagnosis are an important priority area for research and development.

\section{Vascular Dementia}

For vascular dementias ( $\mathrm{VaD})$, traditional classification has been based on the Hachinski Ischemic Score and its modified versions. ${ }^{13,14}$ Currently it is the 1993 National Institute of Neurological Disorders and Stroke-Association Internationale pour la Recherche et l'Enseignement en Neurosciences (NINDSAIREN) criteria that are used most frequently in randomized clinical trials of $\mathrm{VaD}$, with both the "probable $\mathrm{VaD}$ " and "possible VaD" subgroups. ${ }^{15-18}$ The NINDS-AIREN criteria have been reported in clinical pathological correlative studies to have high specificity but low sensitivity. ${ }^{19-21}$ Whereas this is advantageous in the initial acquisition of clinical trials data for $\mathrm{VaD}$ therapy, it leaves an unfulfilled need for criteria with greater sensitivity and broader generalizability to the problem of $\mathrm{VaD}$ in its various forms.

Some of the issues surrounding the sensitivity of these $\mathrm{VaD}$ diagnostic criteria likely result from the reliance or specification that there is a core memory disorder where executive dysfunction is more often the prominent core symptom and where medial temporal lobe structures need not be involved as is the case more typically in AD.

\section{Dementia with Lewy Bodies (DLB)}

The criteria developed by McKeith et $\mathrm{al}^{22}$ have become a standard for studies in DLB. These criteria, have been shown to generally have high specificity (in the range of $85-90 \%$ ), while reports have shown them to have substantially lower sensitivity. ${ }^{23,24}$ However, the inter-rater reliability of DLB criteria remains significantly lower than for other sets of dementia criteria, likely resulting from the heterogeneity of clinical presentation. ${ }^{25}$ Within the symptom cluster of DLB there have been recognized difficulties in defining fluctuations within the core criteria. There is a need to improve diagnostic sensitivity of the DLB criteria, without losing their high specificity, however this may not be resolved until there is a biological test.

\section{Parkinson's Disease Dementia (PDD)}

There are no standard criteria for the diagnosis of PDD. There has been much debate and uncertainty over the relationship between the timing of onset of cognitive decline and the motor Parkinsonian signs. Recent publications have proposed that PDD be defined as having at least one year of motor Parkinsonism before the onset of symptoms of dementia. ${ }^{24,26}$ The biological plausibility of this distinction is uncertain. The necessary understanding of the relationship between DLB and PDD is apparent as both disorders are characterized by an indistinguishable neuropathology, and revised clinical diagnostic criteria will likely be needed to reflect the neuropathological continuum that exists between these disorders.

\section{Frontotemporal Dementia (FTD)}

Two current sets of criteria for the clinical spectrum of disorders related to frontotemporal dementia have been proposed: the Neary criteria of 1998 , which have superseded the older Lund Manchester diagnostic checklist, ${ }^{27,28}$ and the criteria published by the Workgroup on Frontotemporal Dementia and Pick's Disease. ${ }^{29}$ The Neary criteria recommend the term "Frontotemporal lobar degeneration" (FTLD) as the overarching single category that includes three clinical syndromes: frontotemporal dementia, progressive non-fluent aphasia and semantic dementia that are each defined by core and supportive criteria. With their detailed characterization of these recognized subtypes, the Neary criteria have some advantage for use in clinical trials research. Although it is not currently known whether patients within these different phenotypic subtypes respond differently to pharmacological treatment, the availability of these well-defined operational criteria should facilitate such an evaluation. However, there is still no broad consensus presently on FTD/FTLD diagnostic criteria, ${ }^{28-31}$ and terminology $\mathrm{y}^{32,33}$ and this is needed to facilitate the development of therapeutic trials that will optimally evaluate emerging therapies.

\section{Mixed Dementia}

There has been a growing recognition that a significant 
proportion of dementia cases have multiple overlapping neuropathological processes, including vascular, amyloid, tau, and synuclein abnormalities. Clinically this has resulted in mixed dementia diagnoses occurring in increasingly large numbers within dementia cohort studies. ${ }^{10}$ Alzheimer's disease and vascular dementias are the two dementias that most commonly coexist. There is a need for a diagnostic framework on mixed dementia to be developed for research studies and treatment trials. $^{12}$

\section{Mild Cognitive Impairment (MCI)}

The term Mild Cognitive Impairment (MCI) has emerged in the past decade as the most frequently used term to describe the condition of individuals with aging who fall outside of the normal range of cognitive functioning, but do not reach criteria for a diagnosis of dementia. The spectrum of overlapping, but slightly different, conditions in MCI includes Benign Senescent Forgetfulness, Age Associated Memory Impairment (AAMI), Age Associated Cognitive Decline (AACD) and Cognitively Impaired Not Demented (CIND). Common to a number of these defined states, such as MCI, AACD and CIND, are a consistently reported and increased rate of longitudinal progression to dementia diagnosis. ${ }^{34-37}$ Petersen et al have operationalized MCI to include individuals with both subjective and objective memory impairment, with generally normal cognitive function outside of the memory domain, and with normal activities of daily living (ADL) ${ }^{38}$ By definition these individuals do not meet the DSM IV TR criteria for dementia; however, there is considerable debate as to whether this form of MCI is a high risk state of progression to AD or the earliest stage of the disease. ${ }^{38}$ It has been proposed that the constructs around MCI might be better clarified by refinement of ADL assessments, ${ }^{39}$ by careful subclassification of neuro-psychological domains involved, ${ }^{40}$ or by the inclusion of neuroimaging or biomarkers. ${ }^{41}$ The best approach remains a matter of some controversy. ${ }^{42,43}$ An amnestic form of MCI (MCIa) is one clinically defined phenotype of particular interest as a target of therapy. Although intervention at the earliest point in the dementia pathway is clearly desirable, there are a number of issues surrounding MCI that will need resolution to allow it to be an acceptable condition for regulatory approval. In particular, the multiplicity of MCI definitions, the heterogeneity of MCI cohort outcomes based on settings of care, the role of etiological subtypes and the generalizability of the MCIa subgroup to the much larger group of MCI, both in efficacy as well as safety, all need to be further addressed.

\section{Recommendations on Diagnostic Criteria and Approaches for Research Studies}

The current diagnostic standard for dementia, the DSM-IV$T R$, would benefit from movement away from a prerequisite amnestic disorder and towards a set of criteria that might better apply to VaD, PDD, DLB and FTD. Patients with AD and multiple associated disorders, including cerebrovascular disease or Lewy bodies where clinically definable, should also be included within AD drug development to allow sufficient collection of safety and efficacy data for patients with mixed causes of their dementia. As a priority, diagnostic criteria for the earlier identification of $A D$ are required to support earlier treatment interventions. The diagnostic criteria for $D L B$ and $\mathrm{VaD}$ both have high specificity but insufficient sensitivity, which underscores the need for further refinement, while PDD and FTD criteria are still in evolution and would benefit from efforts to establish international consensus criteria. Whether MCI and its amnestic form will be a useful construct for randomized controlled trials (RCTs) remains to be fully evaluated.

\section{Therapeutic APPROACHES FOR DEMENTIA}

\section{Symptomatic Approaches}

In proposing a medication as a putative symptomatic treatment for dementia, it is essential that several issues be addressed. The first is the identification of which symptomatic domains of cognition, behaviour, or function, are the object of treatment. Second, it is mandatory that symptomatic treatment effects be both clinically apparent and meaningful.

The drugs for the symptomatic treatment of $\mathrm{AD}$ that are currently available have been approved by the CNS Division of the Therapeutic Products Directorate (TPD) of Health Canada on the basis of meeting dual primary outcomes, that include a target symptom domain (cognition or behaviour) and a global impression of change. They include the Acetylcholinesterase inhibitors (AChEIs) (donepezil, rivastigmine, and galantamine) for the symptoms of mild to moderate $\mathrm{AD}$; and memantine, the uncompetitive NMDA-receptor antagonist, which has been conditionally approved for the treatment of the symptoms of moderate to severe AD. This same regulatory approach is likely to continue in the future for symptomatic treatments, though targets, including ADLs, should be considered where appropriate, particularly in more advanced disease.

At present, there is no regulatory specification to include a measure of quality of life (QOL) associated with symptomatic improvement, however, it is appreciated that this is an important aspect for patients and their caregivers and its measurement should be encouraged.

\section{Therapies for Disease Modification}

Currently there is a lack of agreement on the methodology to demonstrate disease modification. Proposals have included a delayed start and early withdrawal, however, these have numerous and serious limitations. Proof of a disease-modifying effect would require biological plausibility, a convincing and meaningful change in the disease progression, supported by beneficial effects on biological or imaging markers of the disease.

It is appreciated that symptomatic drugs may also have disease-modifying properties; however, this has yet to be demonstrated. For currently available treatments, a sustained symptomatic benefit is a more realistic target for long-term studies. The methodology for demonstrating a disease modification still requires more development. At the present time the long-term impact of treatment in dementia is best evaluated within survival study designs to the clinical milestones.

\section{Therapies for Disease Prevention}

With the projected growth in the number of dementia patients over the next three decades, ${ }^{1}$ dementia prevention will likely 
become a primary focus of research. The concept of dementia prevention is currently described as delaying the time to onset of diagnosable disease. ${ }^{44}$ Current trials are being conducted in the United States and Europe with a range of three to 12 years. ${ }^{44}$ The number of subjects within these current studies and their associated costs have been prohibitive and are unlikely to be sustainable. Enrichment strategies such as positive family history, apolipoprotein E genotype (E4) will be needed to allow sufficiently high numbers of incident cases to develop within the reasonable timeframe for studies. Prevention studies will also need to be large, take into consideration high drop-out rates, pay particular attention to simple, valid, reliable measures, and to safety. Studies can be nested in other endeavours (e.g., Syst-Eur) which can decrease costs. ${ }^{45}$ The adherence rate to protocol over long periods of study is an important issue within prevention studies.

\section{Recommendations on Therapeutic Approaches for Dementia}

An indication for symptomatic treatment of dementia should be supported by a demonstration of efficacy within at least one of the individual domains of cognition, behaviour, or function in conjunction with a significant benefit on a clinical global measure. Whereas it may be possible to demonstrate a sustained symptomatic benefit at the present time, there is no agreed methodology for a disease-modifying study. Prevention trials are required as they may have the largest public health impact, though there are methodological challenges to make these studies practical and affordable within the Canadian context.

\section{ETHICAL ISSUES}

\section{Standards of Care}

The AChEIs are considered the standard of care for mild to moderate $\mathrm{AD}$ in Canada, ${ }^{46-52}$ although only approximately $25 \%$ of patients with $\mathrm{AD}$ are reportedly treated at the current time. ${ }^{53} \mathrm{~A}$ recent survey found that investigators in $82 \%$ of Canadian dementia clinical research units did not believe that it was possible to recruit to placebo-controlled studies of longer than three months, while $73 \%$ reported that they considered it ethically unacceptable to recruit drug-naïve patients with mild to moderate $\mathrm{AD}$ to a placebo-controlled clinical trial. (Personal communication Dr. Howard Chertkow)

\section{Risk/Benefit Ratio}

With the increasing prevalence of dementia there is pressure to develop therapies more rapidly and to allow their general use as early as possible. As the discussions of the risks and benefits to patients in this process are intensifying, a number of dilemmas are apparent. The progressive nature of these illnesses requires intercession as quickly as possible, while non-judicious use of inadequately tested treatment with doubtful efficacy and significant toxicity can be injurious and is clearly undesirable.

A further concern with respect to emerging biotechnological therapies for $\mathrm{AD}$ is the absence of reliable animal models for investigation. The "new biology" of immune therapies, nerve growth factors, genetically-engineered tissues, and other tissue modifying techniques pose both ill-defined risks and considerable opportunity. While showing therapeutic promise they may also have significant risks. For example, one AD immunotherapy trial with amyloid beta $(\mathrm{Ab})$ was initiated, then discontinued in Phase II when an important and serious meningoencephalitis occurred in $6 \%$ of subjects. ${ }^{54}$ Consideration should be given to testing beyond murine models before taking novel putative disease-modifying treatment into human studies to assist in ascertaining a signal of safety and, where possible, efficacy.

The Canadian Tri-Council Policy Statement, Ethical Conduct for Research Involving Humans (TCPS, 2003) embodies principles for ethical decision-making, with some more clearly defined than others. ${ }^{55}$ The TCPS is the basis upon which Canadian research review boards review their submissions, though it is unclear in its discussion of consent, assent, and proxy-decision-making in dementia. It will also need to be updated and clarified with regard to its consideration of the risk/benefit ratio of specific trials and the participation of vulnerable individuals. Ethical review is a dynamic process, particularly as applications are surfacing with higher risk and a need for more intense ethical debate.

\section{Placebo Use}

The use of placebos in medicine and in medical research has a long and complex history. The legal, ethical, and scientific debate around placebo use is equally complex. ${ }^{56,57}$ Recently, Health Canada and the CIHR established a National Placebo Initiative and a National Placebo Working Committee that recommended that whenever possible "... research subjects in the control group of a trial of a diagnostic, therapeutic, or preventative intervention should receive an established effective therapy." 58 Their document points out that there can be clear distinctions between a treatment that has met regulatory approval and an "established effective therapy". Even when an established effective therapy exists, the possibility of designing an ethically acceptable placebo-controlled trial is not precluded. ${ }^{58}$ However, in practice, with an established standard of care of AchEIs for $\mathrm{AD}$, placebo trials will be used in most circumstances within add-on-designs, where standard therapy is provided to all subjects and either placebo or experimental therapy is added on for the period of research study.

\section{Recommendations on Ethical Issues}

AChEIs represent the standard of care in Canada. The scientific community and industry can no longer rely on a presumed necessity for demonstration of absolute efficacy through a placebo-controlled trial by a regulatory agency as sufficient justification for the study design without provision of a standard of care. Investigators and sponsors will need to carefully and thoughtfully justify the use of a placebo when it is proposed and seek alternative study designs.

\section{Design ANd Methodology Issues}

The prevalence of $\mathrm{AD}$ makes it the main target of experimental therapeutic intervention in dementia. Much of the discussion that follows is therefore centered on $\mathrm{AD}$, though many of the general concepts outlined will also apply to the other dementias. 


\section{Phases of Drug Development}

Traditionally, Phase I studies have been conducted with healthy volunteers, young and old, for the purpose of elucidating kinetics, pharmacodynamics, toxicity and tolerance to pharmacological agents. With treatments targeting the biology of the disease directly, Phase I trials will usually require individuals with the disease rather than healthy volunteers. The traditional role of Phase II studies has been the evaluation of the safety and efficacy of drugs in small, well-defined, restricted patient groups, as well as to obtain signal of efficacy as proof of principle. This usually involves multiple doses, looking for maximum tolerated dose (MTD). For treatments targeting the biology of the disease directly, alternative research pathways to MTD seem likely to be pursued. These may center around the treatment dose that can provide both a biological and clinical response in Phase II, as a prelude to a larger scale Phase II-III trial looking for a clinically-meaningful response in a representative population. ${ }^{59}$ The dose selected may not be related or determined by the MTD. The success of this alternative approach remains to be demonstrated. Open-label extension studies on the active drug after Phase II would be useful sources of the necessary safety data for regulatory approval to proceed to Phase III. Pharmacovigilance after marketing (or a structured Phase IV trial concentrating on safety) is essential to detect unexpected and important adverse effects. There is currently no structured program in Canada for this and this represents an unmet need.

\section{Study Designs}

New agents for the treatment of $\mathrm{AD}$ are most likely to be developed with randomized, controlled trials that allow for the use of the standard of care treatment for all subjects, with the experimental agent or placebo added on. This design will restrict the new indication to add-on therapy, while new monotherapy claims will foreseeably require alternative approaches to add-on designs, including testing for superiority, equivalence and noninferiority. The use of a placebo design without a usual care background will likely be restricted to those patients who are intolerant, those with a non-response to standard pharmacological treatment, or those who give an informed refusal of standard pharmacological care. Each of these scenarios is anticipated to occur infrequently. A further design option is a three-arm trial where there is an experimental treatment, an AChEI and a placebo arm. The size of the placebo arm would be as small as possible, with as short duration of placebo exposure as necessary to demonstrate the requisite efficacy. Some studies have attempted an enrichment technique through a defining of early responders who then continue on a more extended protocol; ${ }^{60}$ however, this is not a currently recommended approach.

Most studies are designed to compare the results on a particular test at time $\mathrm{X}$ between groups. Survival studies (time to a clinically relevant event) will be seen more often, and may be simpler for patients, families, third-party payers and nonexpert professionals to interpret. These types of studies have been tried in $\mathrm{AD}^{61}$

For disease modification the randomized withdrawal design that has been proposed has particular ethical problems, while the randomized start design assumes that the response to an agent (either symptomatic or disease-modifying) is independent of the stage at which the agent is started. ${ }^{62-64}$ Designs based on survival to a clinically meaningful endpoint might solve some of these problems; however, there are a number of considerations that must be resolved to establish widely accepted and appropriate disease milestones. To date, studies have used time to nursing home placement, decline in Clinical Dementia Rating (CDR) stage, loss of ADLs, and death. ${ }^{61}$ Nursing home placement as a disease milestone is complex, as it is determined not only by disease progression but by bed availability, caregivers and other socioeconomic factors that have little to do with pharmaceutical treatment. Death may not be a suitable outcome in dementia if there is prolonged suffering and incapacity in a poor state of health. The delay in losses of ADL may be a suitable outcome; however, there are stage-specific changes and confounding factors can enter into consideration based on settings of care. The emergence of neuropsychiatric symptoms (NPS) has been proposed but phenomenologically NPS may be recurrent and not a suitable permanent dementia milestone. The United States Food and Drug Administration has stated that delaying a clinical milestone in a parallel-group, controlled trial would not be viewed as sufficient evidence for disease modification. ${ }^{65}$ This leaves the unresolved question of whether in the absence of a surrogate biological marker, the demonstration of disease modification is a realistic goal.

Other study designs for dementia also have pitfalls. Multiple cross-over trials are inappropriate for a progressive disease, given that the response at one point in time would not be expected to be the same as the response at a different point in time, precluding the pooling of results from each phase. The use of historical controls is also inappropriate because of the rapid changes in the management of the whole patient with $\mathrm{AD}$, making subjects from even just a few years ago very different from those today.

\section{Statistical Considerations}

Until recently, the gold standard for assessing the efficacy and effectiveness of new medications has been the placebocontrolled, RCT. With a need to advance monotherapy claims in the presence of a standard of care, other study design options include superiority, equivalence, and non-inferiority trials. ${ }^{66}$

In superiority trials, the goal is to establish that the new drug is better (i.e., more effective or with a more benign side-effect profile) than the standard. Because such trials require much larger sample sizes than placebo-controlled studies and are rarely required to bring a drug onto market, they are infrequently done. In equivalence trials, the aim is to show that the new and standard agents have similar degrees of effectiveness or adverse events; however, due to sample size requirements, most studies of new drugs are non-inferiority trials in which it is sufficient to demonstrate that the new drug is not significantly worse than the existing ones. ${ }^{67}$ There are methodological considerations with equivalence and non-inferiority trials, including (a) an inability to determine if the drugs were equally good or equally bad; (b) poorly executed trials with low power can be mistaken for "proving" equivalence or non-inferiority; (c) the equivalence interval is arbitrary; (d) successive non-inferiority trials may lead to a gradual reduction in effectiveness; and (e) often larger trials are necessary. ${ }^{67}$ 
At the analytic level a strict adherence to intention to treat analyses carries difficulties when applied to $\mathrm{AD}$ and other dementias. In dementia trials, subjects often die or withdraw for reasons unrelated to their dementia, and analyses only of completers or with an ITT approach using Last Observation Carried Forward can significantly bias the results. The use of retrieved drop-outs, though theoretically helpful, is difficult to carry out in practice. Studies will need to be designed and analyzed keeping these particular analytic challenges in mind.

\section{Recommendations on Design and Methodology Issues}

It is anticipated that most future placebo controlled RCTs in Canada will allow for a background treatment with current standards of care. The trial designs that involve active controls will change the design and goals of the studies. Although superiority trials are not often performed with the requirement of very large sample sizes, non-inferiority trials and equivalence trials carry risks, such as downward drift of effectiveness and low power being mistaken for 'proof'. Such trials will need to be carefully designed and openly interpreted, with critical consideration by regulatory agencies.

\section{TARGet Symptoms And OUtcome Measures}

The phenomenology of dementia demands that reliable measurement indices be established for cognitive, behavioural, and functional symptoms. For use in trials, measurements should be both ecologically valid and clinically meaningful.

\section{Cognition}

The cognitive section of the Alzheimer's Disease Assessment Scale (ADAS-cog) remains the most widely used cognitive measure in dementia trials ${ }^{68,69}$ and is available in several languages. ${ }^{70}$ It takes 20 to 50 minutes to administer. Memory, orientation, language, construction, and praxis are assessed, while executive function and agnosia are not. Designed for use in $\mathrm{AD}$, the scale may not be ideal for assessing patients with other dementia diagnoses. The ADAS-cog is useful for differentiating $\mathrm{AD}$ patients from controls ${ }^{69}$ and for stratifying dementia severity. ${ }^{71,72}$ Worsening on the ADAS-cog is not linear across disease severity, having both a ceiling and a floor effect. ${ }^{73}$ Patients with moderately severe AD deteriorate more on the ADAS-cog over a year than patients with mild or very severe disease. ${ }^{74}$

Mohs et $\mathrm{al}^{75}$ have investigated some additions to the ADAS$\operatorname{cog}$ and found that a cancellation task is sensitive across a range of dementia severities. A word learning task with delayed recall and a maze task may be useful additions in studying patients with early dementia or MCI.

The ADAS-cog has been used within a number of recent MCI studies where its utility as an outcome measure will be evaluable. ${ }^{76,77}$ It has also been used in drug trials for vascular and mixed dementia and has demonstrated sensitivity and reliability to measure change longitudinally in these conditions. ${ }^{17,78,79}$

In more advanced dementia the most widely used assessment tool is the Severe Impairment Battery (SIB). ${ }^{80,81}$ The domains tested are analogous to those assessed by the ADAS-cog. The SIB is reliable and valid and its utility has been demonstrated in moderate to severe dementia. ${ }^{82-86}$

The Mini-Mental State Exam (MMSE) ${ }^{87}$ is often used to classify dementia severity. Floor and ceiling effects are limiting, ${ }^{88,89}$ with scores being affected by both age and education. $^{90}$ Although the MMSE has been included as an outcome measure in trials, ${ }^{91-93}$ its main use has been as an inclusion criterion. It is part of the lexicon that allows an understanding by the wider clinical community around subjects selected for trials.

Remarkably little is known about the specificity of symptomatic medications for particular cognitive domains, even though this may provide important insight into treatment response. As medications are developed in the future it is foreseeable that more focused testing of specified cognitive domains with neuropsychological testing may be a preferred approach to investigate potential treatment benefits. Inclusion of more fine-grained neuropsychological testing, particularly of executive function, should be encouraged at least as secondary outcome measures in trials. ${ }^{94}$

\section{Recommendations on Cognition}

The ADAS-cog remains the most widely used cognitive outcome measure in dementia trials of mild to moderate severity and is likely to remain so, particularly for AD. The SIB is useful in studying patients with advanced dementia facilitating measurement where floor effects of the ADAS cog and MMSE are encountered. The MMSE remains useful for stratifying $A D$ patients for trial entry. The best cognitive outcome measure for MCI and for the other dementias remains a matter for future elaboration. For clinical trials, measures of symptomatic domains should be valid, and should sample from the cognitive domains relevant to the clinical expression and likely to respond to treatment.

\section{Neuropsychiatric Symptoms}

Neuropsychiatric symptoms (NPS) are common in dementia. They increase in prevalence with severity and are a major source of disability, patient distress, caregiver burden, and cost, and are an important determinant of nursing home placement. ${ }^{95,96}$ This grouping of symptoms includes disorders of mood, behaviour as well as psychosis. Given both their clinical and social importance, antidementia therapies should be directed at NPS including aggression, psychosis and mood as specific treatment targets. ${ }^{97}$

Mood assessment is of particular importance, yet the actual diagnosis of depression in dementia is complex and requires a high level of clinical knowledge and acumen, as well as second party collateral information. Instruments that have been specifically developed to assess mood in the non-demented population, such as the Hamilton Depression Rating Scale ${ }^{98}$ and the Montgomery-Asberg Depression Rating Scale, ${ }^{99}$ may be useful in mildly demented individuals, but they are not reliable in the later stages of dementia when language and comprehension have declined significantly. The Geriatric Depression Scale, which is widely used in clinical practice, has been shown to be unreliable in those with increased cognitive impairment. ${ }^{100-102}$ Many of the global neurobehavioural rating instruments do include mood items; however, their clinical significance has not been established. 
In studies where the assessment of mood in dementia is of major importance, it is preferable to use an instrument that has been developed specifically for dementia, and which integrates caregiver information into the rating. Two useful instruments for clinical trials that focus on mood as an outcome measure are the Dementia Mood Assessment Scale and the Cornell Scale for Depression in Dementia. ${ }^{103,104}$ The Dementia Mood Assessment Scale was developed for rating the severity of depressed mood in mild to moderate AD. ${ }^{103}$ It was modelled on the Hamilton Depression Rating Scale but excludes items that are more subjective and therefore prone to error. For patients who are more severely demented, the Cornell Scale is a better choice, as it is a caregiver-rated scale that is particularly suited to differentiating between cognitive and mood symptoms, and is sensitive to treatment effects over a wide range of depression and dementia severity. ${ }^{104}$

Outside of depression, rating instruments designed specifically to measure the spectrum of NPS in dementia are generally caregiver-rated. The Neuropsychiatric Inventory (NPI) is particularly useful as it is brief and addresses a wide range of symptoms. ${ }^{105}$ It measures 12 domains and has been validated with evidence of reliability and sensitivity to measure change within clinical trials. Concerns about the NPI scale include some difficulties in the metrics of the scale as well as the wide variance that is seen within the trials that have included it. ${ }^{106,107}$ The Behavioural Pathology in AD Scale (BEHAVE-AD) is also considered to be a valid and reliable scale that measures 25 behaviours in seven clusters. ${ }^{108}$ It includes a global assessment of caregiver distress and has been used within a number of RCTs demonstrating both reliability and sensitivity to change. ${ }^{109,110}$ The behavioural rating scale for dementia of the Consortium to Establish a Registry for Alzheimer's Disease (CERAD-BRSD) is another useful instrument that measures 46 items in eight clusters. ${ }^{111}$ Unlike the BEHAVE-AD, it evaluates the frequency of behavioural symptoms as opposed to their severity.

The Cohen-Mansfield Agitation Inventory (CMAI) is the best-known instrument for the detailed evaluation of agitation. ${ }^{112}$ The original version assesses 29 different items and was developed for use in nursing homes although its use has been extended to other settings. It is particularly useful when a study is being considered around the target symptom of agitation.

\section{Recommendations on Neuropsychiatric Symptoms}

Neuropsychiatric symptoms in dementia are both highly prevalent and an important cause of distress to patients and families. They represent an important symptomatic target of therapy and they merit consideration of regulatory labeling where data demonstrating therapeutic efficacy and safety can be demonstrated. For both depression and other NPS, there are dementia-specific scales that have been validated and have been shown to be responsive and reliable at measuring treatment effects.

\section{Functional Disability}

Functional decline and loss of activities of daily living (ADLs) are core features of dementia. ${ }^{5}$ In $\mathrm{AD}$, this decline begins insidiously and deteriorates gradually. It usually progresses hierarchically, starting with demanding occupational tasks, followed by instrumental activities of daily living (IADLs), and finally affecting the basic ADLs (bADLs), such as dressing, personal hygiene, and continence. ${ }^{113}$ The ADL status can also be used to chart the course of the disease, having utility as a prognostic marker, and significantly contributing to caregiver burden and institutionalization. ${ }^{96}$ For these reasons, functional assessment has been widely used as an outcome measure in treatment trials of dementia and is emerging as a useful coprimary outcome measure particularly in more advanced dementia.

Functional decline results from a complex interaction of factors, including cognitive decline (particularly executive dysfunction), behaviour, motor skills, perceptual and sensory abilities, medical comorbidities, and social variables. ${ }^{114}$ The loss of functional autonomy does not, however, invariably parallel the loss of cognitive function.

The ADL scales have been specifically developed for use in the assessment of $\mathrm{AD}$, and have been integrated as outcome measures in clinical trials with cholinesterase inhibitors and memantine. The most widely used scales are the Alzheimer Disease Functional Assessment and Change Scale (ADFACS), ${ }^{115}$ the Disability Assessment for Dementia (DAD), ${ }^{116}$ the Alzheimer's Disease Cooperative Study-Activities of Daily Living (ADCS-ADL), ${ }^{117}$ and the Progressive Deterioration Scale (PDS). ${ }^{118}$ These scales share some common features. They each assess both ADLs and IADLs, are based on an interview with the caregiver, and can be completed within 15-20 minutes. Only the DAD assesses the hierarchical manner with which function declines cross referenced to the cognitive processing involved for each item. ${ }^{116}$ All of these scales have been validated and have been used in trials involving predominantly patients with AD. Their utility and continuing validation will be needed for use in other types of dementia.

\section{Recommendations on Functional Disability}

There are ADL scales that have been developed and validated to measure functional disability across the spectrum of diagnosed dementia. The ADLs are an essential outcome for inclusion within the investigations of treatments for dementia. In more advanced dementia ADLs are a suitable target as a coprimary outcome measure, while further research is still needed relating to functional disability at the mild cognitive impairment stage.

\section{Global Assessments}

Global assessment measures particularly using the Clinician's Global Impression of Change (CGIC) or the Clinician's Interview Based Impression of Change (CIBIC) have long been a mainstay in dementia drug trials. Though they have been a regulatory specified primary outcome measure in antidementia trials for the FDA, they also have found acceptance from clinicians. They require skilled judgments to be made by experienced clinicians about whether treatment has been associated with clinically detectable change at the individual patient level. As a dual primary outcome measure within dementia RCTs, they ensure that in addition to a statistically significant effect on a primary objective psychometric or other outcome, there is also a clinically detectable global change. The 
CIBIC-plus assessment, which requires caregiver input as well as patient assessment, has been validated and has been shown to have both measurement sensitivity and reliability in AD. ${ }^{119}$

Other global measures, such as the CDR and the Global Deterioration Scale (GDS), ${ }^{120,121}$ which consist of descriptions of patient characteristics in a variety of symptomatic domains (e.g., memory, behaviour, functioning), as well as social domains (e.g., home and hobbies, community affairs, personal care, ADLs), allow an alternative approach to the CGIC/CIBIC-plus. ${ }^{122}$ To judge where a patient falls on these various domains, clinicians either conduct a semi-structured interview with ratings of each domain or complete an aggregate rating with all clinical information available following the assessment. The CDR allows both an overall stage as well as a sum of the individual domains to be determined, while the GDS provides a specified stage. These global assessments have been used in many clinical trials, particularly in those longer than six months.

The experience with global clinical measures to date suggests that the above approaches both can identify treatment effects of about the same order of magnitude as the ADAS-Cog; ${ }^{123-125}$ but they do not identify the same patients as benefiting. ${ }^{126}$ However, there are important limitations to the use of global assessments that should encourage refinements in future research studies. The currently available global rating scales do not consider patient preferences in evaluating the clinical meaningfulness of antidementia drugs. Furthermore, there have also been recent data demonstrating that the CIBIC-plus, as it is currently operationalized, has a limited ability to detect improvement as opposed to decline, a deficiency that will need to be addressed as treatment opportunities with larger effect sizes become available for testing. ${ }^{127}$

\section{Recommendations on Global Assessments}

The use of global assessments as a primary outcome measure has both clinical and ecological validity. Beyond objective measures of benefit on psychometric testing, the global assessment establishes that treatment effects are clinically identifiable. Refinements to global assessments are needed to allow patient improvement to be reliably captured as there are larger treatment effect sizes in the coming generation of therapeutic interventions.

\section{Quality of Life}

There is a growing consensus that QOL is an important outcome for assessing the effectiveness of dementia interventions, but, to date, there is no agreement about how to measure it. ${ }^{97,128-134}$ Generally, disease-specific measures are more responsive (i.e., sensitive to disease-related changes over time), while generic measures facilitate comparisons across disease states and are more useful for policy decisions. ${ }^{135}$ Several dementia-specific QOL measures have been developed (e.g., QOL-Alzheimer's Disease and Dementia QOL), and these, along with various generic QOL instruments, have been used to assess QOL in dementia patients. The QOL measures vary with respect to content, respondent, method of administration, and target population.

Until recently, there was a focus on proxy and observational QOL measures, because it was believed that dementia patients could not rate their own QOL; ${ }^{136,137}$ however, there is now substantial evidence to suggest that a majority of mild-moderate dementia patients can meaningfully rate their own QOL. ${ }^{138-143}$ In addition, data from studies using a variety of QOL measures have consistently shown significant differences between patient rated and caregiver proxy rated QOL, and between ratings by different proxy sources. ${ }^{141,144-150}$

Although some QOL measures have evidence supporting their reliability and validity for use in dementia populations, there are virtually no data about the responsiveness of these measures to change with treatment intervention. ${ }^{134}$ In addition, little is known about the impact of various potential confounders (e.g., comorbidity, patient's living circumstance) on patient and proxy QOL ratings. To date, few dementia clinical trials have included patient QOL as an outcome. ${ }^{151} \mathrm{~A}$ number of AChEI trials used a poorly validated generic QOL measure that exhibited marked variability and inconsistent results, ${ }^{93,152-154}$ while other trials used The Progressive Deterioration Scale (PDS), which was developed as a dementia-specific QOL measure. ${ }^{155-159}$ Most consider the PDS to be a measure of daily activities rather than of QOL.

Since dementia interventions may also affect the QOL of caregivers, this should also be measured in dementia trials. ${ }^{160-164}$ Some generic QOL measures have been used to assess caregiver QOL, with little known about their responsiveness to intervention studies.

\section{Recommendations on Quality of Life}

Patient and caregiver QOL outcome measures should be included in studies of antidementia therapies, though at this time, no specific measures can be recommended. Diseasespecific measures will likely be more responsive to treatment effects, while generic measures may be necessary to address policy issues, such as cost-effectiveness. For patients with mild to moderate dementia, both patient- and proxy-rated $Q O L$ measures are encouraged, as they appear to provide different information. For patients with severe dementia, proxy and/or observational QOL measures are recommended. Future studies are needed to clarify the criteria for inclusion of patients for selfrating and for identifying the most appropriate proxy informants; to identify the characteristics of patients and proxies that influence their QOL ratings over time; and to determine which QOL measures are the most reliable, valid, and responsive for specific dementia populations.

\section{Biological Markers}

There are important potential roles for biomarkers within antidementia treatment studies. The Consensus Report of the Working Group on Molecular and Biochemical Markers of AD outlined many of the issues surrounding the use of biomarkers within research studies and created a reference framework that is still the most influential. ${ }^{165}$ The forthcoming Alzheimer Disease Neuroimaging Initiative (ADNI) is the largest National Institutes of Health (NIH)-funded research study yet undertaken to advance the development of dementia biomarkers.

Biomarkers have the potential to assist in the accurate identification of suitable patient populations for inclusion within trials and to reduce sample sizes through the collection of more homogeneous study groups. They may allow the diagnostic distinction to be made between elderly normals, subjects with 
MCI at high risk of progressing to dementia, and individuals with dementia of differing etiologies. They may allow study populations to be enriched with those at high risk of progression or with a particularly distinctive course. Ideally they will also allow for the measurement of response to both symptomatic and disease modifying therapy. As biomarkers mature they will certainly complement clinical and neuropsychological evaluations, but they may also eventually evolve into useful surrogate endpoints in AD research. These markers may also provide important mechanistic clues to the pharmacological action of anti-dementia compounds. At the present time, however, their place within antidementia drug trials is adjunctive to the necessary clinical outcomes.

\section{CSF and Blood Biomarkers}

There is a long list of putative cerebrospinal fluid (CSF) and blood biomarkers that have generated interest as diagnostics for $\mathrm{AD}$ and other dementias. Virtually all of these are at the level of research interest still requiring additional confirmation. The greatest current interest in CSF markers are those that are most fundamental to the pathological footprint of $\mathrm{AD}$. The CSF phosphorylated tau (CSF p-tau) proteins are the only biomarkers with currently demonstrated sensitivity and specificity sufficient to serve as a useful diagnostic biomarker. ${ }^{166}$ Specificities and sensitivities are reported in the $85-90 \%$ range at distinguishing $\mathrm{AD}$ from other dementias as well as distinguishing MCI that will progress. ${ }^{167} \mathrm{Ab} 1-42$ has been measured in both plasma and CSF with poor correlation between CSF levels and disease duration and severity. Its utility in distinguishing $\mathrm{AD}$ from other dementias is still uncertain. CSF p-tau (alone or with CSF Ab measures) could potentially enhance the homogeneity of patients entering MCI trials; ${ }^{167}$ however, there is no proven utility of any blood or CSF marker in monitoring disease progression at this point.

It is foreseeable that a panel of disease markers might prove advantageous. It will also be important to develop "noninvasive" markers utilizing readily obtainable tissue samples to monitor disease progression or regression. The assays themselves will need to be reproducible, reliable, and relatively inexpensive. To facilitate future biomarker development, it will be highly advantageous to collect and store biological specimens as an adjunct to current clinical trials research in AD.

\section{Recommendations on Biological Markers, CSF and Blood Biomarkers}

Development of surrogate disease markers - from imaging, CSF samples, and blood tests - has the potential to stimulate drug development and clinical trials in the dementias. There are a set of highly promising current biomarkers that have the potential to reach the level of disease surrogates in the future, but all require shared collection of data, standardization, and longitudinal assessment of their relationship to disease progression and treatment. Data must be amassed not only at the group level, but anticipating the individual variability (largely genetic) which may influence drug response. Collection of such data in the course of RCTs should be encouraged as complementary endpoints. They are not at present recommended to replace clinical outcomes but only to provide supportive evidence. The DNA banking and genotype profiling during trials will open the way to more effective pharmacogenomics in the future.

\section{Neuroimaging: PET, MRI, MRS, SPECT}

Use of neuroimaging parameters as outcome measures in the development of new therapies is continually advancing and this pace will continue to accelerate in the coming decade. The MRI is currently being tested in RCTs, particularly using volumetric measures. ${ }^{168}$ However, these measures remain non-standardized and variable between centres. Centralized reading and extensive efforts to standardize the neuroimaging at each site, including scanning phantoms, may reduce some of the variability and increase reliability. While the technologies for cerebral functional measurement are available through the use of positron emission tomography (PET) or functional MRI (fMRI), their routine use has been restricted by technical complexity, cost, and lack of sufficient experience to establish correlations to clinical outcomes. Recent technological advances, including novel ligands for PET, and increasingly standardized scientific data collection and interpretation, may allow for their use in antidementia drug development. ${ }^{169,170}$

\section{Recommendations on Neuroimaging}

Promising neuroimaging cannot be accepted as a surrogate endpoint in antidementia drug trials at the present time. However, further research to validate, standardize and establish sensitivity and specificity of these neuroimaging markers may advance these modalities. The variability among labs awaits improvement, and the whole range of possible neuroimaging modalities currently remains as a set of biomarkers rather than surrogate endpoints. Measures such as hippocampal volumetrics, fMRI memory activation in $A D$ and quantitative MRI lesion measurements in VaD, are steadily improving.

\section{Pharmacogenomics}

Pharmacogenomics holds the potential to predict which individuals have a greater chance of either benefit or harm from pharmacological intervention. If this working hypothesis were to be verified through research in dementia, this would be particularly significant as it is the large constituency of elderly patients on multiple medications that are the major users of antidementia treatments. To date, there are no reliable pharmacogenomic predictors of response to currently available dementia therapies. The apolipoprotein E genotype has been investigated in some detail with the acetycholinesterase inhibitors, but has lacked consistent predictive ability across studies and remains of uncertain utility. In their draft guideline on this topic entitled: Guidance for Industry: Pharmacogenomic Data Submission, ${ }^{171}$ the FDA indicated their belief that pharmacogenomic analyses can be smoothly integrated into drug development processes while there has been an expressed interest by the European regulatory authorities to include a DNA banking program with apoE genotype profiling in dementia RCTs. 


\section{Therapeutic Approaches to Alzheimer's Disease}

\section{Mild to Moderate Alzheimer's disease}

Mild to moderate AD has most often been operationally defined for RCTs by MMSE total scores of 10 to 26, inclusively. ${ }^{87}$ This definition does not take into account the many dimensions of dementia that fall outside of the MMSE scale's ability to define severity. Revised definitions of mild to moderate that do not exclusively rely on the MMSE or other cognitive tests and which take into account levels of functional disability and neuropsychiatric symptoms are needed.

The criticisms of the existing Phase III trials have been that they have included too highly selected populations, with outcomes measures that are useful in trials but have no clinical applicability outside of the trial setting. The RCTs including only NINCDS-ADRDA “probable AD” subjects exclude a significant percentage of individuals with "possible AD" whose trajectory of disease course is probably similar and whose inclusion would improve study generalizability. Subjects with significant NPS are most often systematically excluded. There are other opportunities to develop and include more clinically meaningful outcomes, with pre-specified minimally significant clinical differences. Exclusion criteria (e.g., comorbid conditions, medications) should be minimized in an effort to improve the generalizability of results. Cognitive rehabilitation interventions in $\mathrm{AD}$ are a potential treatment approach that require an evidence base to be developed through research studies to define their utility.

\section{Recommendations on Therapeutic Approaches to Mild to Moderate AD}

Both subjects with NINCDS-ADRDA "possible" and "probable" $A D$ should be evaluated in $A D$ clinical trials. Subjects with a potential second etiology contributing to their dementia need to be studied as well. A balance between study sample homogeneity and the generalizability of study results is needed through the development process of antidementia treatments. There is still a need to develop valid, reliable, sensitive, relevant and comprehensive measures of treatment effects. Minimal clinically significant differences should be predetermined and used in evaluating the results of these studies. Subjects with significant NPS should be included in RCTs.

\section{Moderate to Severe Alzheimer's disease}

The clinical features of more advanced AD, in the moderate to severe stages, include greater functional losses, increased levels of neuropsychiatric symptoms and an increasing burden of illness for caregivers. ${ }^{95,121,164}$ The neuropathological and neurochemical changes of advanced AD may distinguish the moderate to severe stages from earlier disease stages, however, the distinctions are not readily made with current in vivo technologies. From a societal perspective, data from the Canadian Study of Health and Aging (CSHA) have suggested that the costs of the illness rise very significantly in transition from mild to severe disease. ${ }^{2}$ Despite the obvious importance of moderate to severe $\mathrm{AD}$, there have been few treatment trials in this population. In Canada, memantine has received conditional regulatory approval for the symptomatic treatment of moderate to severe AD. There is a strong rationale for attention to this stage of dementia severity as CSHA estimated that the prevalence of moderate to severe dementia was $50 \%$ of all cases of dementia. ${ }^{1}$

For the purposes of RCTs, subjects with moderate to severe $\mathrm{AD}$ can be distinguished from milder disease through the combination of a global staging instrument and a screening cognitive measure. The GDS stage 5-7 or CDR stage 2-5 are recommended for global staging. ${ }^{120-122}$ For cognitive screening in moderate to severe trials, average MMSE scores should be no higher than 12, and should have a range of inclusion from 0 to 15. Until there is an approved standard of care for severe AD, trials should be randomized and double-blind with placebo controls. In the future, when a standard of care for severe AD is established, a design to allow all patients being treated with "standard care" and then an add- on design will likely be needed with the provision that for a monotherapy claim there will be a need for direct head-to-head designed RCTs.

Outcome measures in moderate to severe AD trials must address stage specific symptoms. Since small changes in cognitive function may have questionable clinical relevance at this stage, primary outcomes should include a global rating, and might alternatively include a functional or behavioural coprimary outcome measure. The CIBIC-plus has been successfully used in previous RCTs in this population. ${ }^{107}$ There is some suggestion that it relies heavily on ADLs and behavioural changes, which is appropriate for moderate to severe AD. Function can be measured with the ADCS/ADLSEV or DAD, though both scales are limited in long-term care settings. NPS at these stages can be measured with the NPI and efforts to include subjects with significant NPS in RCTs are well justified. The SIB is currently recommended as a cognitive outcome measure.

Stabilization of function, behaviour, and cognition are all reasonable goals of therapy, and potentially more realistic than significant improvement at this stage. Pharmacoeconomic outcomes are important and might focus on indirect costs, such as caregiver time, which make up a significant proportion of costs for community dwelling patients.

\section{Recommendations on Therapeutic Approaches to Moderate to Severe AD}

The methodology and outcomes in moderate to severe $A D$ trials face different issues than those of milder stages. The inclusion criteria require both a functional and a cognitive global measure to define the target study group. Until there is a standard of care for moderate to severe $A D$, placebo-controlled parallel group trials are recommended. When a standard of care becomes available, add-on therapy designs or non-inferiority to the standard of care are most likely to be used to demonstrate efficacy of new therapies. For a symptomatic indication in moderate to severe $A D$, functional disability or behavioral symptoms are an alternatively suitable primary outcome measure beyond cognition, while global ratings are an important co-primary outcome in this patient group.

\section{Therapeutic Approaches to Mild Cognitive Impairment}

Recently, there have been trials of therapeutic interventions targeted at slowing the rate of progression in MCI. The MCIa has been used within a current generation of randomized placebo 
controlled parallel group clinical trials of the AChEIs and rofecoxib. ${ }^{76,172,173}$ The anticipation within these trials was that the use of MCIa as a diagnostic construct would allow the accrual of homogeneous MCI study samples and predictably high rates of conversion ranging from $10-15 \%$ per annum. From the preliminary presentations of these studies, as well as from previous population studies, ${ }^{174}$ it has become apparent that small differences in the MCIa inclusion criteria, in the cut-off points on neuropsychological tests of episodic memory, in the exclusion criteria or in the AD diagnostic conversion criteria, all impact on the rates of progression to dementia in RCTs. Careful interpretation of this variability will be required in determining whether this is a problem with the validity of the MCIa construct, the treatments being used or the underlying heterogeneity of MCIa that have yet to be reconciled.

It was estimated in a study of Canadian dementia referral clinics that only $25 \%$ of MCI is MCIa. This leaves the largest group of referred subjects with MCI outside of the MCIa studies. ${ }^{10}$ From a regulatory perspective, it can be anticipated that were a successful MCIa RCT to be reported, there would still be the need to address the clinical heterogeneity and efficacy of the therapy of MCI more broadly within a usual care setting, as it would need to be demonstrated that treatment is both safe and efficacious in usual care settings.

\section{Recommendations on Therapeutic Approaches to MCI}

There is recognition and general acceptance that MCI represents an intermediate state of cognitive function that falls outside of normal without meeting criteria for dementia. Still unresolved is its utility as a suitable target for antidementia therapy to delay the progression of cognitive impairment to dementia. The first generation of RCTs using MCIa as the diagnostic construct have demonstrated that apparently small differences in inclusion, exclusion and conversion to dementia criteria are associated with variable outcomes. This has raised some controversy about the validity of the MCIa as a construct for use in clinical trials, and the way that this might be advanced or improved. It can be anticipated in future drug development targeted at MCI that a positive study in MCIa done in dementia research settings will need to be replicated within usual care settings to ensure safety and efficacy of treatment before it would be appropriate for approval in usual care community settings.

\section{Therapeutic Approaches to Vascular Dementia}

Vascular dementia (VaD) is an etiologically heterogeneous disorder arising from a variety of cerebrovascular diseases (CVD), and resulting in cognitive impairments that reflect the degree and location of the underlying vascular damage. The term Vascular Cognitive Impairment (VCI) has been proposed as an alternative nosology that may gain a foothold in future clinical trials. Vascular Cognitive Impairment is a term that is inclusive of $\mathrm{VaD}$ and its subtypes, Vascular Cognitive Impairment No Dementia (VCIND), and mixed AD and CVD (AD/CVD). ${ }^{175,176}$ It reflects the important and diverse causes of vascular injury and the related patterns of cognitive impairment. Within VCI particular attention has been directed at the subcortical ischemic vascular subtype that results from ischemic injury associated with small vessel disease. ${ }^{177,178}$
It can be readily appreciated that with this heterogeneity of mechanisms of cerebrovascular injury and related subgroups, the design and methodology of clinical trials will be challenging particularly as it may relate to regulatory approval for a vascular indication. Though great strides have been made in developing neuroimaging for $\mathrm{VCI} / \mathrm{VaD}$, there are still gaps in lesion identification, including the detection of microinfarcts, which are an important correlate of cognitive impairment. Advances in neuroimaging do hold the promise of better definition to the $\mathrm{VaD}$ disorder and improved diagnostic sensitivity. However, there is currently no readily available imaging technique that can identify the presence of mixed AD and CVD, which may be the most common form of $\mathrm{VaD}$.

Clinical trials to date have focused on "clinically probable" and "possible" VaD by the NINDS-AIREN criteria with some beneficial effects evident for different drug classes, including the AChEIs and memantine. ${ }^{17,18,179,180}$ The lack of converging and consistent results to achieve regulatory approval of any of these drugs for $\mathrm{VaD}$ has raised the question of whether it is the therapy or the study methodology that is lacking. These RCTs have adapted cognitive test instruments and outcome measures from AD studies. While these instruments were developed and validated in $\mathrm{AD}$, their measurement sensitivity and reliability in $\mathrm{VaD}$ are uncertain. The placebo groups in these RCTs have not declined as predicted, suggesting that their decline is slower and their course different than AD. The value of tests of executive function and neuropsychiatric symptoms in $\mathrm{VaD}$ has been largely overlooked and need to be included in future trials. To date it has been difficult to address the etiological heterogeneity within the VaD/VCI framework where different mechanisms of vascular injury might also have differential response to treatment. The RCTs to date have had insufficient power to examine the etiologically relevant CVD subgroups.

Among the other lessons learned from the recently completed generation of clinical trials is the advantage of using welldefined neuroimaging criteria with centralized reading and standardized protocols, including advanced techniques, such as diffusion tensor imaging. Follow-up scanning to quantify changes in tissue atrophy, and lesion burden is becoming feasible, though not yet validated as a surrogate outcome. Akin to blood storage, scans can also be archived for future analysis.

\section{Recommendations on Therapeutic Approaches to VaD}

Designs and approaches for future trials will depend on the evolving concepts of VCI and VaD which are etiologically heterogeneous and may have differential potential to respond to particular interventions. The methodology of VaD trials has suffered from a dependence on AD outcome measures with an unmet need to develop sensitive and valid VaD outcome measures. It is recommended that more sensitive measures of executive functioning be included, as well as ADL and behavioural assessments. The advantages of centralized reading and standardized neuroimaging entry criteria to RCTs are now recognized and will benefit future trials. Longer trial periods may be required to discern clinically meaningful benefits. 


\section{Therapeutic Approaches to Parkinson's Disease Dementia ANd Dementia with Lewy Bodies}

Parkinson's Disease Dementia and Dementia with Lewy Bodies are pathologically overlapping conditions. They represent a spectrum of dementias that is very challenging for clinician management as they face a unique mix of neuropsychiatric symptoms including hallucinations/delusions, progressive cognitive impairment and movement disorders. They are uniquely sensitive to the negative effects of dopamineblocking neuroleptic medications that are associated with increased morbidity and increased mortality. ${ }^{24}$

Within the last decade the first placebo controlled RCTs have been undertaken in these disorders. These studies have underscored some of the important conceptual and methodological challenges. "Probable DLB" as defined by the McKeith criteria is an infrequent disorder for which RCT recruitment has been very difficult. ${ }^{23}$ A large scale RCT did not meet its recruitment targets citing both administrative delays and recruitment difficulties in some centers. ${ }^{181}$ For PDD there is still a lack of consensus definition. ${ }^{26}$ There are unanswered questions over the natural history of these disorders and there are a lack of validated outcome measures. As with vascular dementia, there is a tendency to call on outcome measures that have been validated for use within $\mathrm{AD}$ trials, though there are important differences in the cognitive and neuropsychiatric symptoms that would make the $\mathrm{AD}$ outcomes more insensitive probes than those that might be developed and validated for DLB/PDD. The use of biomarkers, including neuroimaging with PET, MRI and SPECT and CSF markers as outcome measures in PDD and DLB, require further investigation to determine their sensitivity and reliability within clinical trials and their use within RCTs is encouraged to advance their development. Clinical scales that evaluate autonomic function and motor parkinsonism may be useful adjuncts.

Beyond open-label and case series reports of the AChEIs in PDD and DLB, the double-blind randomized placebo-controlled trials in DLB and PDD have been performed with positive outcomes allowing that regulatory submissions might be forthcoming. ${ }^{181,182}$ In an RCT of rivastigmine in PDD the primary outcomes were the ADAS cog and the CGIC while in a DLB trial the primary outcome measures were the NPI total scores and a combined score from selected tests from the cognitive drug research computerized cognitive assessment system. ${ }^{182}$

Anti-psychotic agents, such as clozapine and quetiapine, have been reported to benefit both DLB and PDD. ${ }^{183-186}$ Two randomized placebo-controlled trials of clozapine have shown benefit for psychotic symptoms in PD, but only included patients with mild PDD. There have been no published placebocontrolled RCTs of PDD or DLB with atypical anti-psychotic agents. Additional studies of these and other agents are necessary in these patient groups.

To advance the future designs of clinical trials in PDD and DLB, there will be a need to orient outcome measures around clinically important milestones such as time to onset of dementia in PD, the loss of function abilities, falls, nursing home placement, QOL and mortality.

\section{Recommendations on Therapeutic Approaches to PDD and $D L B$}

Parkinson's Disease Dementia and Dementia with Lewy Bodies are both significant causes of dementia for which there is an important unmet need for treatment. The pitfalls and limitations of current therapies should drive the pursuit of therapies with outcomes that are clinically important including the time to onset of dementia, cognitive and behavioural impairment, functional decline, falls, nursing-home placement, mortality, and QOL. It may become both necessary and desirable to combine PDD and DLB with Parkinsonism in large scale RCTs. Motor impairment has been the focus of PD trials and must be assessed in patients with PDD and DLB. Conversely, cognitive impairment should be assessed in trials targeting motor impairment in PD. The move away from AD outcome measures to validated measures for PDD and DLB is needed.

\section{Therapeutic Approaches to Frontotemporal Dementia}

Notwithstanding the different proposed nosologies for the spectrum of disorders related to FTD or FTLD, ${ }^{187}$ it is generally agreed that these dementias most commonly occur under age 70 years, and account for an estimated $12 \%$ of dementia cases with onset under 65 years of age. ${ }^{188-190}$

Despite their recognized importance as a cause of dementia and the rationale for therapies targeting serotonergic and dopaminergic systems, there have been no large-scale treatment trials in FTD. ${ }^{191-193}$ A wide variety of drugs have been reported to have benefits including trazodone, ${ }^{194,195}$ idazoxan, ${ }^{196}$ lithium plus fluoxetine ${ }^{197}$ and paroxetine, ${ }^{197}$ fluoxetine, ${ }^{198,199}$ sertraline, ${ }^{198,199}$ fluvoxamine, ${ }^{200}$ paroxetine, ${ }^{198,199,201}$ 1-deprenyl, ${ }^{202}$ moclobenide, ${ }^{203}$ and methylphenidate. ${ }^{204}$ However, only two studies are double-blind, placebo-controlled trials: a case study using idazoxan and a group trial using trazodone. ${ }^{195,196}$

Although the general principals for therapeutic trials in AD will be applicable to FTD, there are no standards of care for FTD allowing that for FTLD, placebo-controlled trials will be both ethical and necessary.

Early FTD affects primarily social cognition, which may reflect orbitofrontal involvement; however, most standard frontal neuropsychological tests are sensitive to dorsolateral frontal function and relatively insensitive to orbitofrontal function. ${ }^{31,205}$ Therapeutic trials in FTD in turn will need to include measures of social cognition, such as Theory of Mind tasks, and tests of orbitofrontal function that are also sensitive to FTD but that are outside the social cognitive realm, such as Object Alternation. ${ }^{205-207}$ Ideally, a single global measure of social cognition/orbitofrontal function should be developed to minimize the number of primary outcome measures. Candidates for tests of other frontal functions to supplement the social cognitive/orbitofrontal measures include the Executive Interview, ${ }^{208}$ Frontal Assessment Battery, ${ }^{209}$ and Addenbrooke's Cognitive Examination. ${ }^{210}$ More selective tasks such as Wisconsin Card Sorting Test and clock drawing should also be considered. ${ }^{211,212}$

Other potential primary outcome measures for symptomatic RCTs in FTD could include NPS evaluated with the NPI,105 Frontal Behavioral Inventory, ${ }^{213-215}$ and Frontal Systems 
Behavior Scale (FrSBe) as well as global assessments. ${ }^{216,217}$ Measures of functional assessment, caregiver stress, and QOL should also be considered as secondary outcomes. Study groups should span the full range of severity in FTD, with outcome measure selected that are stage sensitive. Whereas the MMSE is standard for staging clinical severity in $\mathrm{AD}$, it is relatively insensitive to early FTD. Severity measures to consider include the NPI, FBI, and FrSBe. ${ }^{105,213-217}$

Management of PPA and SD focuses on speech-language treatments rather than pharmacological approaches. Future developments could lead to drug trials in these conditions, and, the general principles outlined for FTD apply to PPA and SD.

\section{Recommendations on Therapeutic Approaches to FTLD}

The currently available treatments for FTD/FTLD are limited with a large unmet need for therapy that can treat both the symptoms and the disease process across these dementia subtypes. There are currently no formal standards for therapeutic trials in FTD/FTLD, underscoring the need to define consensus standards for clinical trials. The outcome measures for FTD/FTLD will not be interchangeable with AD and they will have to address the different cognitive and neuropsychiatric impairments that are present in these conditions. Consensus working groups may be necessary to advance clinical trial designs and methods for this spectrum of dementia.

\section{FUtURE DEVELOPMENTS}

The search for effective medicines has benefited enormously from the unprecedented growth in our understanding of mechanisms of neurodegenerative disease and the elaboration of the pathological bases of the dementias. This new knowledge is allowing a more focussed approach to treatments based on pathogenic targets. Of course, this will be only the first step as the ultimate approach will be to prevent the changes that underline the functional decline. The development pipeline includes approaches that aim to protect the brain from damage by reactive oxygen species or inflammation, ${ }^{218-220}$ that can stimulate nerve regeneration and can either prevent or enable the removal of the protein aggregates that form the neuropathological tombstones of neurodegeneration. ${ }^{221}$ There are now strong grounds for believing that compounds that act to prevent or reverse amyloid plaque formation will modify the progression of $\mathrm{AD}$ and possibly related forms of dementia. ${ }^{222-228}$ In the next few years, many medicines directed at these targets will enter Phase II and Phase III clinical trials. Anti-amyloid therapies, antioxidants, stem cells, nerve growth factors, insulin modulating approaches and neurotransmitter based therapies are all on the visible horizon of clinical trials. ${ }^{218-229}$

\section{SUMMARY}

These Canadian Guidelines have evolved through a broad collaboration of the 2nd Canadian Conference on the Development of Antidementia Therapies among academic and clinical experts, representatives of the regulatory authorities of Health Canada and the Alzheimer Society of Canada. They serve to update the initial set of 1995 Canadian Guidelines for the Development of Antidementia Therapies. A set of Guidelines, developed through the process undertaken for this Conference, provides a point of common reference to clinical researchers, government agencies and the pharmaceutical/biotechnology industries engaged in the therapeutic development in this field.

The approach taken by the conference was "oracle-based" with topic review and presentation by recognized experts who were asked to reference evidence-based data where it existed, and to craft recommendations within each topic area. They were also asked to provide working recommendations and expert opinion where there was no substantive evidence base or where opinions were disparate but where some guidance was still desirable. The Conference did not adhere to a consensus-based approach with voting and with levels of evidence, rather the authorship of this paper was charged with providing a unifying synthesis of the presentations and discussions at the meeting, and the written submissions of the presenters.

These Canadian Guidelines are unique for having been peerreviewed and then published within a peer-reviewed journal. This has allowed for significant feedback prior to publication, as well as for the anticipated discussion in the broader community that will follow their publication. They stand apart from the more usual process where draft guidelines are developed by the Regulatory agencies with some consultation from the expert community. At the same time, there are clearly significant limitations to Guidelines that are developed in this way. In some topic areas, generalizations may have been made that overrepresent the opinions of the community of experts that convened for the meeting. The response of the community-atlarge to this publication may help address this deficiency and is encouraged. In the development of the Guidelines, outside of the conference, there was no formal process for presenting dissenting opinions and these may not have been fully represented in the final Guidelines. Though there was participation and input received from the representatives of the Regulatory agency through discussion at the Conference, to date these published Guidelines have not been accorded any formal standing as an official government-endorsed Guidelines and should not be construed as having such standing.

A reflection of the progress in this field of dementia can be appreciated in comparing the current Guidelines with those of 1995. Our updated list of topic areas, covered in detail in the current Guidelines, in many instances were only alluded to in the 1995 version of the Guidelines. At the same time, there are significant uncertainties that are apparent within a variety of these topic areas. Mild Cognitive Impairment (MCI) was one such area, and was the topic that led to the most contentious discussion. Whereas there was general agreement that it represents a state of cognitive function that falls outside of normal for age and short of dementia by formal criteria, it was unclear whether the amnestic form MCIa will survive as a meaningful diagnostic construct or defining characteristic suitable for clinical trials. The heterogeneity of populations enrolled and outcomes of RCTs that have used this MCIa is apparent and not fully resolved. In the area of VaD RCTs the adoption of $\mathrm{AD}$ clinical trials methodology and outcomes has likely hampered the ability to evaluate emerging therapies. The necessity for standardization of the neuroimaging criteria for RCTs is now recognized for $\mathrm{VCI} / \mathrm{VaD}$ as is the need for longer study durations to address some of the more important clinical outcomes and changes that occur in this condition. For PDD and 
DLB, there is a fundamental uncertainty over whether these are discrete clinical disorders that should be evaluated separately in RCTs or whether they are part of a continuum with pathological overlap that should allow them to be studied together in larger scale RCTs. In FTD there is a large unmet need for treatment and there are no formal standards yet for therapeutic trials.

This Conference concludes that there is room to define consensus standards for clinical trials outside of $\mathrm{AD}$ and that this might well be undertaken even in advance of promising candidate therapeutic interventions. Finally, among the new topics is the area of mixed dementia, where there has been a growing recognition that a significant proportion of dementia cases do have multiple overlapping neuropathological processes. The regulatory input is that some definition of mixed dementia will be needed, with data presented to receive therapeutic labeling for such conditions whose inclusion in RCTs is recommended.

It is clear, from the reflections of the progress of the past ten years and the challenges outlined, that the development of Guidelines will not be a static process. There will be a foreseeable future need to update these 2004 Guidelines. The Conference is optimistic that this future challenge will be met in time and that the current set will serve us well.

\section{REFERENCES}

1. Canadian study of health and aging working group. Canadian study of health and aging: Study methods and prevalence of dementia. CMAJ. 1994; 150: 899-913.

2. Hux MJ, O'Brien BJ, Iskedjian M, et al. Relation between severity of Alzheimer's disease and costs of caring. CMAJ. 1998; 159: 45765

3. Mohr E, Feldman H, Gauthier S. Canadian guidelines for the development of antidementia therapies: a conceptual summary. Can J Neurol Sci. 1995; 22: 62-71.

4. McKhann G, Drachman DA, Folstein M, et al. Clinical diagnosis of Alzheimer's disease - report of the NINCDS-ADRDA Work Group under the auspices of Department of Health and Human Services Task Force on Alzheimer's disease. Neurology. 1984; 34: $939-44$

5. American Psychiatric Association. Diagnostic and Statistical Manual of Mental Disorders. (IV-TR). Washington, D.C.: 2000.

6. Morris J, McKeel DW, Fulling K, Torack RM, Berg L. Validation of clinical diagnostic criteria for Alzheimer's disease. Ann Neurol. 1988; 24: 17-22.

7. Lopez OL, Swihart AA, Becker JT, et al. Reliability of NINCDSADRDA clinical criteria for the diagnosis of Alzheimer's disease. Neurology. 1990; 40: 1517-22.

8. Mayeux R, Saunders AM, Shea S, et al. Utility of the apolipoprotein E genotype in the diagnosis of Alzheimer's disease. N Engl J Med. 1998; 338: 506-11.

9. Hyman BT, Trojanowski JQ. Consensus recommendations for the postmortem diagnosis of Alzheimer disease from the National Institute on Aging and the Reagan Institute Working Group on diagnostic criteria for the neuropathological assessment of Alzheimer disease. J Neuropathol Exp Neurol. 1997; 56: 1095-7.

10. Feldman H, Levy AR, Hsiung GY, et al. A Canadian cohort study of cognitive impairment and related dementias (ACCORD): Study methods and baseline results. Neuroepidemiology. 2003; 22: 26574.

11. Massoud F, Devi G, Stern Y, et al. A clinicopathological comparison of community-based and clinic-based cohorts of patients with dementia. Arch Neurol. 1999; 56: 1368-73.

12. Lopez OL, Becker JT, Klunk W, et al. Research evaluation and diagnosis of possible Alzheimer's disease over the last two decades: pt 2. Neurology. 2000; 55: 1863-9.

13. Hachinski VC, Lassen NA, Marshal J. Multi-infarct dementia: a cause of mental deterioration in the elderly. Lancet. 1974; 2: 20710
14. Rosen WG, Terry RG, Fuld PA, Katzman R, Peck A. Pathological verification of ischemic score in differentiation of dementias. Ann Neurol. 1980; 7: 486-8.

15. Roman GC, Tatemichi TK, Erkinjuntti T, et al. Vascular dementia: diagnostic criteria for research studies. Report of the NINDSAIREN International Workshop. Neurology. 1993; 43: 250-60.

16. Erkinjuntti T, Kurz A, Gauthier S, et al. Efficacy of galantamine in probable vascular dementia and Alzheimer's disease combined with cerebrovascular disease: a randomised trial. Lancet. 2002; Apr 13; 359(9314): 1283-90.

17. Black S, Roman GC, Geldmacher DS, et al. Efficacy and tolerability of donepezil in vascular dementia: positive results of a 24-week, multicenter, international, randomized, placebo-controlled clinical trial. Stroke. 2003 Sep 11; 34: 2323-30.

18. Wilkinson D, Doody R, Helme R, et al. Donepezil in vascular dementia: a randomized, placebo-controlled study. Neurology. 2003; 61: 479-86.

19. Chui HC, Mack W, Jackson JE, et al. Clinical criteria for the diagnosis of vascular dementia: a multicenter study of comparability and interrater reliability. Arch Neurol. 2000; 57: 191-6.

20. Pohjasvaara T, Mantyla R, Ylikoski R, Kaste M, Erkinjuntti T. Comparison of different clinical criteria (DSM-III, ADDTC, ICD-10, NINDS-AIREN, DSM-IV) for the diagnosis of vascular dementia. National Institute of Neurological Disorders and Stroke-Association Internationale pour la Recherche et l'Enseignement en Neurosciences. Stroke. 2000; 31: 2952-7.

21. Gold G, Bouras C, Canuto A, et al. Clinicopathological validation study of four sets of clinical criteria for vascular dementia. Am J Psychiatry. 2002; 159: 82-7.

22. McKeith IG, Galasko D, Kosaka K, et al. Consensus guidelines for the clinical and pathological diagnosis of dementia with Lewy bodies (DLB): report of the consortium on DLB international workshop. Neurology. 1996; 47: 1113-24.

23. McKeith IG, Perry EK, Perry RH. Report of the second dementia with Lewy body international workshop. Neurology. 1999; 53 : 902-5.

24. McKeith I, Mintzer J, Aarsland D, et al. Dementia with Lewy bodies. Lancet Neurol. 2004; 3: 19-28.

25. Lopez OL, Litvan I, Catt KE, et al. Accuracy of four clinical diagnostic criteria for the diagnosis of neurodegenerative dementias. Neurology. 1999; 53: 1292-9.

26. Emre M. Dementia associated with Parkinson's disease. Lancet Neurol. 2003; 2: 229-37.

27. Lund and Manchester Groups. Clinical and neuropathological criteria for frontotemporal dementia. J Neurol Neurosurg Psychiatry. 1994; 57: 416-8.

28. Neary D, Snowden JS, Gustafson L, et al. Frontotemporal lobar degeneration: a consensus on clinical diagnostic criteria. Neurology. 1999; 51: 1546-54.

29. McKhann GM, Albert MS, Grossman M, et al. Clinical and pathological diagnosis of frontotemporal dementia: report of the Work Group on Frontotemporal Dementia and Pick's Disease. Arch Neurol. 2001; 58: 1803-9.

30. Brun A, Englund B, Gustafson L, et al. Clinical and neuropathological criteria for frontotemporal dementia. J Neurol Neurosurg Psychiatry. 1994; 57: 416-8.

31. Gregory CA, Serra-Mestres J, Hodges JR. Early diagnosis of the frontal variant of frontotemporal dementia: how sensitive are standard neuroimaging and neuropsychologic tests? Neuropsychiatry Neuropsychol Behav Neurol. 1999; 12: 128-35.

32. Hodges JR, Miller B. The classification, genetics and neuropathology of frontotemporal dementia. Introduction to the special topic papers: (pt 1). Neurocase. 2001; 7: 31-5.

33. Kertesz A, Munoz DG. Pick's disease and Pick complex. Toronto: Wiley-Liss, 1998.

34. Graham JE, Rockwood K, Beattie BL, et al. Prevalence and severity of cognitive impairment with and without dementia in an elderly population. Lancet. 1997; 349: 1793-6.

35. Crook T, Bartus R, Ferris SH, et al. Age-associated memory impairment: proposed diagnostic criteria and measures of clinical change - report of a National Institute of Mental Health Work Group. Dev Neuropsychol. 1986; 2: 261-76. 
36. Levy R. Aging-associated cognitive decline. Int Psychogeriatr. 1994; 6: 63-8.

37. Ebly EM, Hogan DB, Parhad IM. Cognitive impairment in the nondemented elderly: Results from the Canadian Study of Health and Aging. Arch Neurol. 1995; 52: 612-9.

38. Petersen RC, Smith GE, Waring SC, et al. Mild cognitive impairment: clinical characterization and outcome. Arch Neurol. 1999; 56: 303-8.

39. Royall DR, Chiodo LK, Polk MJ. Misclassification is likely in the assessment of mild cognitive impairment. Neuroepidemiology. 2004; 23: 185-91.

40. Winblad B, Palmer K, Kivipelto $M$, et al. Mild cognitive impairment--beyond controversies, towards a consensus: report of the International Working Group on Mild Cognitive Impairment. J Intern Med. 2004; 256: 240-6.

41. Jack CRJ, Petersen RC, Xu YC, et al. Prediction of AD with MRIbased hippocampal volume in mild cognitive impairment. Neurology. 1999; 52: 1397-403.

42. Ingles JL, Fisk JD, Merry HR, Rockwood K. Five-year outcomes for dementia defined solely by neuropsychological test performance. Neuroepidemiology. 2003; 22: 172-80.

43. DeCarli C, Mungas D, Harvey D, et al. Memory impairment, but not cerebrovascular disease, predicts progression of MCI to dementia. Neurology. 2004; 63: 220-7.

44. Standridge JB. Pharmacotherapeutic approaches to the prevention of Alzheimer's disease. Am J Geriatr Pharmacother. 2004; 2: 119-32.

45. Forette F, Seux ML, Staessen JA, et al. Prevention of dementia in randomised double-blind placebo-controlled Systolic Hypertension in Europe (Syst-Eur) trial. Lancet. 1998; 352: 1347-51.

46. Patterson C, Gauthier S, Bergman $\mathrm{H}$, et al. The recognition, assessment and management of dementing disorders: conclusions form the Canadian Consensus Conference on Dementia. Can J Neurol Sci. 2001; 28 Suppl 1: S3-16.

47. American Psychiatric Association. Practice guidelines for treatment of patients with Alzheimer's disease and other dementias of late life. Am J Psychiatry. 1997; 154 Suppl 5: 1-39.

48. Fillit H, Cummings J. Practice guidelines for the diagnosis and treatment of Alzheimer's disease in a managed care setting: part II-Pharmacologic therapy. Alzheimer's Disease (AD) Managed Care Advisory Council. Manag Care Interface. 2000; 13: 51-6.

49. Doody RS, Stevens JC, Beck C, et al. Practice parameter: management of dementia (an evidence-based review). Report of the Quality Standards Subcommittee of the American Academy of Neurology. Neurology. 2001; 56: 1154-66.

50. NICE issues guidance on drugs for Alzheimer's disease. National Institute for Clinical Excellence. Available from: http://www. nice.org.uk/article.asp?a=14406.

51. California Workgroup on Guidelines for Alzheimer's Disease Management Guidelines for Alzheimer's Disease Management Available from: http://www.alzla.org/medical/FinalReport 2002.pdf

52. Doody RS. Current treatments for Alzheimer's disease: cholinesterase inhibitors. J Clin Psychiatry. 2003; 64 Suppl 9: S11-7.

53. Reichman WE. Current pharmacologic options for patients with Alzheimer's disease. Ann Gen Hosp Psychiatry. 2003; 2: 1.

54. Orgogozo JM, Gilman S, Dartigues JF, et al. Subacute meningoencephalitis in a subset of patients with $\mathrm{AD}$ after Abeta42 immunization. Neurology. 2003; 61: 46-54.

55. Tri-Council Policy Statement: Ethical Conduct for Research Involving Humans, Medical Research Council of Canada, Natural Sciences and Engineering Research Council of Canada, Social Sciences and Humanities Research Council of Canada. Public Works and Government Services Canada, June 2003.

56. Shapiro E, Shapiro A. The powerful placebo: from ancient priest to modern physician. Baltimore: The John Hopkins University Press Ltd; 1997.

57. Guess HA, Kleinman A, Kusek JW, Engel LW, editors. The science of the placebo. London: BMJ Books; 2002.
58. National Placebo Working Committee, Draft Report, Health Canada and the Canadian Institutes for Health Research, 2003. Available from: http://www.cihr-irsc.gc.ca/e/services/19301.shtml.

59. Gervais F, Garceau D, Aisen P, Gauthier S. Glycosaminoglycan mimetics in Alzheimer's disease. In: Gauthier S, Scheltens P, Cummings J, editors. Alzheimer Disease and related disorders annual. London: Taylor and Francis; 2005.

60. Davis KL, Thal LJ, Gamzu ER, et al. A double-blind placebocontrolled multicenter study of tacrine for Alzheimer's Disease. The Tacrine Collaborative Study Group. N Engl J Med. 1992; 327: 1253-9.

61. Sano M, Ernesto C, Thomas RG, et al. A controlled trial of selegeline, alpha-tocopherol, or both as treatment for Alzheimer's disease. N Engl J Med. 1997; 336: 1216-22.

62. Leber P. Slowing the progression of Alzheimer disease: methodologic issues. Alzheimer Dis Assoc Disord. 1997; 11 Suppl 5: S10-21.

63. Whitehouse PJ, Kittner B, Roessner M. Clinical trial designs for demonstrating disease-course-altering effects in dementia. Alzheimer Dis Assoc Disord. 1998; 12: 281-94

64. Mani RB. The evaluation of disease modifying therapies in Alzheimer's disease: a regulatory viewpoint. Stat Med. 2004; 23 : 305-14.

65. Leber P. Guidelines for the clinical evaluation of antidementia drugs. US FDA, Washington DC, 1990.

66. Fleischhacker WW, Czobor P, Hummer M, et al. Placebo or active control trials of antipsychotic drugs? Arch Gen Psychiatry. 2003; 60: 458-64.

67. Streiner, DL. Unicorns do exist: a tutorial on "proving" the null hypothesis. Can J Psychiatry. 2003; 48: 756-61.

68. Mohs RC, Rosen WG, Davis KL. The Alzheimer's disease assessment scale: An instrument of assessing treatment efficacy. Psychopharmacol Bull. 1983; 19: 448-50.

69. Rosen WG, Mohs RC, Davis KL. A new rating scale for Alzheimer's disease. Am J Psychiatry. 1984; 141: 1356-64.

70. Verhey FR, Houx P, Van Lang N, et al. Cross-national comparison and validation of the Alzheimer's disease assessment scale: results from the European Harmonization Project for Instruments in Dementia (EURO-HARPID). Int J Geriatr Psychiatry. 2004; 19: 41-50.

71. Zee R, Landreth E, Vicari S, et al. Alzheimer's disease assessment scale: a subtest analysis. Alzheimer Dis Assoc Disord. 1992; 6: 164-81.

72. Doraiswamy PM, Bieber F, Kaiser L, et al. Memory, language, and praxis in Alzheimer's disease: norms for outpatient clinical trial populations. Psychopharmacol Bull. 1997; 33: 123-8.

73. Van Belle G, Uhlmann R, Hughes JP, Larson E. Reliability of estimates of change in mental status test performance in senile dementia of the Alzheimer type. J Clin Epidemiol. 1990; 43: 38995 .

74. Schmeidler J, Mohs RC, Aryan M. Relationship of disease severity to decline on specific cognitive and functional measures in Alzheimer disease. Alzheimer Dis Assoc Disord. 1998; 12: 14651.

75. Mohs RC, Knopman D, Petersen RC, et al. Development of cognitive instruments for use in clinical trials of antidementia drugs: additions to the Alzheimer's disease assessment scale that broaden its scope. The Alzheimer's disease Cooperative Study. Alzheimer Dis Assoc Disord. 1997; 11 Suppl 2: S13-21.

76. Grundman M, Petersen RC, Ferris SH, et al. Mild cognitive impairment can be distinguished from Alzheimer disease and normal aging for clinical trials. Arch Neurol. 2004; 61: 59-66.

77. Salloway S, Ferris S, Kluger A, et al. Efficacy of donepezil in mild cognitive impairment: A randomized placebo-controlled trial. Neurology. 2004; 64: 651-7.

78. Bullock R, Erkinjuntti T, Lilienfeld S, et al. Management of patients with Alzheimer's disease plus cerebrovascular disease: 12-month treatment with galantamine. Dement Geriatr Cogn Disord. 2004; 17: $29-34$

79. Wilcock G, Mobius HJ, Stoffler A, et al. A double-blind, placebocontrolled multicentre study of memantine in mild to moderate vascular dementia (MMM500). Int Clin Psychopharmacol. 2002; 17: 297-305. 
80. Saxton J, Swihart AA. Neuropsychological assessment of the severely impaired elderly patient. Clin Geriatr Med. 1989; 5: 531-43.

81. Schmitt FA, Cragar D, Ashford JW, et al. Measuring cognition in advanced Alzheimer's disease for clinical trials. J Neural Transm. Suppl 2002; 62: 135-48.

82. Schmitt FA, Ashford W, Ernesto C, et al. The severe impairment battery: concurrent validity and assessment of longitudinal change in Alzheimer's disease. Alzheimer Dis Assoc Disord. 1997; 11 Suppl 2: 551-6.

83. Panisset M, Roudier M, Saxton J, Boller F. Severe impairment battery: a neuropsychological test for severely demented patients. Arch Neurol. 1994; 51: 41-5.

84. Tariot PN, Farlow MR, Grossberg GT, et al. Memantine treatment in patients with moderate to severe Alzheimer's disease already receiving donepezil: a randomized controlled trial. JAMA. 2004; 291: 317-24.

85. Gauthier S, Feldman H, Hecker J, et al. Functional, cognitive, and behavioural effects of donepezil in patients with moderate Alzheimer's disease. Curr Med Res Opin. 2002; 18: 347-54.

86. Prasher VP, Huxley A, Haque MS, et al. A 24-week, double-blind, placebo-controlled trial of donepezil in patients with Down Syndrome and Alzheimer's disease - pilot study. Int J Geriatr Psychiatry. 2002; 17: 270-8.

87. Folstein MF, Folstein SE, McHugh PR. Mini-Mental State: a practical method for grading the cognitive state of patients for the clinician. J Psychiatr Res. 1975; 12: 189-98.

88. Ihl R, Frolich L, Dierks T, Martin EA, Maurer K. Differential validity of psychometric tests in dementia of the Alzheimer type. Psychiatry Res. 1992; 44: 93-106.

89. Reisberg B, Ferris SH, Franssen EH, et al. Mortality and temporal course of probable Alzheimer's disease: a 5-year prospective study. Int Psychogeriatr. 1996; 8: 291-311.

90. Crum RM, Anthony JC, Bassett SS, Folstein MF. Population-based norms for the Mini-Mental State Examination by age and educational level. JAMA. 1993; 18: 2386-91.

91. Courtney C, Farrell D, Gray R, et al. Long-term donepezil treatment in 565 patients with Alzheimer's disease (AD2000): randomized double-blind trial. Lancet. 2004; 363(9427): 2105-15.

92. Jones RW, Soininen H, Hager K, et al. A multinational, randomized, 12 -week study comparing the effects of donepezil and galantamine in patients with mild to moderate Alzheimer's disease. Int J Geriatr Psychiatry. 2004; 19: 58-67.

93. Rogers SL, Farlow MR, Doody RS, Mohs R, Friedhoff LT. A 24week, double-blind, placebo-controlled trial of donepezil in patients with Alzheimer's disease. Donepezil Study Group. Neurology. 1998; 50: 136-45.

94. Sahakian BJ, Owen AM, Morant NJ, et al. Further analysis of the cognitive effects of tetrahydroaminoacridine (THA) in Alzheimer's disease: assessment of attentional and mnemonic function using CANTAB. Psychopharmacology (Berl). 1993; 110: $395-401$

95. Cummings JL, Back C. The cholinergic hypothesis of neuropsychiatric symptoms in Alzheimer's disease. Am J Geriatr Psychiatry. 1998; 6 Suppl 1: S64-S78.

96. Hope T, Keene J, Gedling K, Fairburn CG, Jacoby R. Prediction of institutionalization for people with dementia living at home with a carer. Int J Geriatr Psychiatry. 1998; 13: 682-90.

97. Winblad B, Wimo A, Almkvist O. Outcome measures in Alzheimer's disease: do they go far enough? Dement Geriatr Cogn Disord. 2000, 11 Suppl 1: 3-10.

98. Hamilton M. A rating scale for depression. J Neurol Neurosurg Psychiatry. 1960; 23: 56-62.

99. Montgomery SA, Asberg M. A new depression scale designed to be sensitive to change. Br J Psychiatry. 1979; 134: 382-9.

100. Burke WJ, Houston MJ, Boust SJ, Roccaforte WH. Use of the Geriatric Depression Scale in dementia of the Alzheimer type. J Am Geriatr Soc. 1989; 37: 856-60.

101. Feher EP, Larrabee GJ, Crook TH 3rd. Factors attenuating the validity of the Geriatric Depression Scale in a dementia population. J Am Geriatr Soc. 1992; 40: 906-9.

102. Gilley DW, Wilson RS. Criterion-related validity of the Geriatric Depression Scale in Alzheimer's disease. J Clin Exp Neuropsychol. 1997; 19(4): 489-99.
103. Sunderland T, Minichiello M. Dementia mood assessment scale. Int Psychogeriatr 1996; 8 Suppl 3: 329-31.

104. Alexopoulos GS, Abrams RC, Young RC, et al. Cornell scale for depression in Dementia. Biol Psychiatry. 1988; 23: 271-84.

105. Cummings JL, Mega M, Gray K, et al: The Neuropsychiatric Inventory: comprehensive assessment of psychopathology in dementia. Neurology. 1994; 44: 2308-14.

106. Morris JC, Cyrus PA, Orazem J, et al. Metrifonate benefits cognitive, behavioral, and global function in patients with Alzheimer's disease. Neurology. 1998; 50: 1222-30.

107. Feldman H, Gauthier S, Hecker J, et al. A 24-week, randomized, double-blind study of donepezil in moderate to severe Alzheimer's disease. Neurology. 2001; 57: 613-20.

108. Reisberg B, Borenstein J, Salob SP, et al. Behavioral symptoms in Alzheimer's disease: phenomenology and treatment. J Clin Psychiatry. 1987; 48 Suppl: S9-15.

109. Katz IR, Jeste DV, Mintzer JE, et al. Comparison of risperidone and placebo for psychosis and behavioral disturbances associated with dementia: a randomized, double-blind trial. Risperidone Study Group. J Clin Psychiatry. 1999; 60: 107-15.

110. De Deyn PP, Rabheru K, Rasmussen A, et al. A randomized trial of risperidone, placebo, and haloperidol for behavioral symptoms of dementia. Neurology. 1999; 53: 946-55.

111. Tariot PN, Mack JL, Patterson MB, et al. The behavioral rating scale for dementia of the Consortium to Establish a Registry for Alzheimer's Disease. Am J Psychiatry. 1995; 152: 1349-57.

112. Cohen-Mansfield J. Agitated behaviors in the elderly. II. Preliminary results in the cognitively deteriorated. J Am Geriatr Soc. 1986; 34: 722-7.

113. Reisberg B. Functional assessment staging (FAST). Psychopharmacol Bull. 1988; 24: 653-9.

114. Gelinas I, Auer S. Functional autonomy. In: Gauthier S, editor. Clinical diagnosis and management of Alzheimer's disease. Second Edition Revised editor. London: Martin Dunitz; 2001: p. 213-26.

115. Mohs RC, Doody RS, Morris JC, et al. A 1-year, placebo-controlled preservation of function survival study of donepezil in AD patients. Neurology. 2001; 57: 481-8.

116. Gelinas I, Gauthier L, McIntyre M, Gauthier S. Development of a functional measure for persons with Alzheimer's disease: the disability assessment for dementia. Am J Occup Ther. 1999; 53: 471-81.

117. Galasko D, Bennett D, Sano M, et al. An inventory to assess activities of daily living for clinical trials in Alzheimer's disease. The Alzheimer's Disease Cooperative Study. Alzheimer Dis Assoc Disord. 1997; 11 Suppl 2: S33-9.

118. DeJong R, Osterlund OW, Roy GW. Measurement of quality-of-life changes in patients with Alzheimer's disease. Clin Ther. 1989; 11 : 545-54.

119. Schneider LS, Olin JT, Doody RS, et al. Validity and reliability of the Alzheimer's Disease Cooperative Study-Clinical global impression of change. Alzheimer Dis Assoc Disord. 1997; 11 Suppl 2: S22-32.

120. Hughes CP, Berg L, Danzinger WL. A new clinical scale for the staging of dementia. Br J Psychiatry. 1982; 140: 566-72.

121. Reisberg B, Ferris SH, de Leon MJ, Crook T. The global deterioration scale for assessment of primary degenerative dementia. Am J Psychiatry. 1982; 139: 1136-9.

122. Morris JC. The Clinical Dementia Rating (CDR): current version and scoring rules. Neurology. 1993; 43: 2412-4.

123. Rockwood, K. Size of the treatment effect on cognition of cholinesterase inhibition in Alzheimer's Disease. J Neurol Neurosurg Psychiatry. 2004; 75: 677-85.

124. Livingston G, Katona C. How useful are cholinesterase inhibitors in the treatment of Alzheimer's disease? A number needed to treat analysis. Int J Geriatr Psychiatry. 2000; 15: 203-7.

125. Whitehead A, Perdomo C, Pratt RD, et al. Donepezil for the symptomatic treatment of patients with mild to moderate Alzheimer's disease: a meta-analysis of individual patient data from randomized controlled trials. Int J Geriatr Psychiatry. 2004; 19: 624-33.

126. Rockwood K, Graham J, Fay S. Goal setting and attainment in Alzheimer's disease patients treated with donepezil. J Neurol Neurosurg Psychiatry. 2002; 73: 500-7. 
127. Quinn J, Moore M, Benson DF, et al. A videotaped CIBIC for dementia patients: validity and reliability in a simulated clinical trial. Neurology. 2002; 58: 433-7.

128. Mack JL, Whitehouse PJ. Quality of Life in Dementia: state of the art--report of the International Working Group for Harmonization of Dementia Drug Guidelines and the Alzheimer's Society satellite meeting. Alzheimer Dis Assoc Disord. 2001; 15: 69-71.

129. Whitehouse PJ, Orgogozo JM, Becker RE, et al. Quality-of-life assessment in dementia drug development. Position paper from the International Working Group on Harmonization of Dementia Drug Guidelines. Alzheimer Dis Assoc Disord. 1997; 11 Suppl 3: S56-60.

130. Maslow K, Whitehouse P. Defining and measuring outcomes in Alzheimer's disease research: conference findings. Alzheimer Dis Assoc Disord. 1997; 11 Suppl 6: S186-95.

131. Berg L, Montgomery R. Metrics of effectiveness within Alzheimer's disease research and across diseases. Alzheimer Dis Assoc Disord. 1997; 11 Suppl 6: S181-3.

132. Jonker C, Gerritsen D, Bosboom P, et al. A model for quality of life measures in patients with dementia: Lawton's next step. Dement Geriatr Cogn Disord. 2004; 18: 159-64.

133. Selai C, Trimble MR. Assessing quality of life in dementia. Aging Ment Health. 1999; 3: 101-11

134. Ready RE, Ott BR. Quality of life measures for dementia. Health Qual Life Outcomes. 2003; 1: 11-19.

135. Guyatt GH, Feeny DH, Patrick DL. Measuring health-related quality of life. Ann Intern Med. 1993; 118: 622-9.

136. Logsdon RG. Making the most of every day: quality of life in Alzheimer's disease. In: Harris PB, editor. The Person with Alzheimer's Disease: pathways to understanding the experience. Baltimore: Johns Hopkins Press; 2002. p.75-87.

137. Brod M, Stewart AL, Sands L. Conceptualization of quality of life in dementia. J Mental Health and Aging. 1999; 5: 7-19.

138. Kane RA, Kling KC, Bershadsky B, et al. Quality of life measures for nursing home residents. J Gerontol A Biol Sci Med Sci. 2003; 58: $240-8$.

139. Selai CE, Trimble MR, Harvey RJ. Assessing quality of life in dementia: preliminary psychometric testing of the Quality of Life Assessment Schedule (QOLAS). Neuropsychological Rehabilitation. 2001; 11: 219-43.

140. Mozley CG, Huxley P, Sutcliffe C, et al. "Not knowing where I am doesn't mean I don't know what I like": cognitive impairment and quality of life responses in elderly people. Int $\mathrm{J}$ Geriatr Psychiatry. 1999; 14: 776-83.

141. Logsdon RG, Gibbons LE, McCurry SM, Teri L. Assessing quality of life in older adults with cognitive impairment. Psychosom Med. 2002; 64: 510-19.

142. Brod M, Stewart AL, Sands L, et al. Conceptualization and measurement of quality of life in dementia: the dementia quality of life instrument (DQoL). Gerontologist. 1999; 39: 25-35.

143. Sprangers MA, Aaronson NK. The role of health care providers and significant others in evaluating the quality of life of patients with chronic disease: a review. J Clin Epidemiol. 1992; 45: 743-60.

144. Ready RE, Ott BR, Grace J. Patient versus informant perspectives of quality of life in mild cognitive impairment and Alzheimer's disease. Int J Geriatr Psychiatry. 2004; 19: 256-65.

145. Sands LP, Ferreira P, Stewart AL, et al. What explains differences between dementia patients' and their caregivers' ratings of patients' quality of life? Am J Geriatr Psychiatry. 2004; 12: 272-80.

146. Edelman P, Fulton BR, Kuhn D. Comparison of dementia-specific quality of life measures in adult day centres. Home Health Care Serv Q. 2004; 23: 25-42.

147. Novella JL, Jochum C, Jolly D, et al. Agreement between patients' and proxies' reports of quality of life in Alzheimer's disease. Qual Life Res. 2001; 10: 443-52.

148. Mador J, Clark M, Crotty M, et al. Utility-weighted measures of quality of life in Alzheimer's disease. Alzheimer Dis Assoc Disord. 2002; 16: 202-3

149. Coucill W, Bryan S, Bentham P, et al. EQ-5D in patients with dementia: an investigation of inter-rater agreement. Med Care. 2001; 39: 760-71.
150. Karlawish JH, Casarett D, Propert KJ, et al. Relationship between Alzheimer's disease severity and patient participation in decisions about their medical care. J Geriatr Psychiatry Neurol. 2002; 15 : 68-72.

151. Santaguida P, Raina P, Booker L, et al. Pharmacological Treatment of Dementia: Evidence Report/Technology Assessment No. 97 (Prepared by McMaster University Evidence-based Practice Center under Contract No. 290-02-0020). AHRQ Publication No. 04-E018-2. Rockville, MD: Agency for Healthcare Research and Quality; April 2004.

152. Rogers SL, Doody RS, Mohs RC, et al. Donepezil improves cognition and global function in Alzheimer's disease. Arch Intern Med. 1998; 158: 1021-31.

153. Burns A, Rossor M, Hecker J, et al. The effects of donepezil in Alzheimer's disease: results from a multinational trial. Dement Geriatr Cogn Dis. 1999; 10: 237-44.

154. Rogers SL, Friedhoff LT. The efficacy and safety of donepezil in patients with Alzheimer's disease: results of a US multicentre, randomized, double-blind, placebo-controlled trial. The Donepezil Study Group. Dementia. 1996; 7: 293-303.

155. Winblad B, Engedal K, Soininen H, et al. A 1-year randomized, placebo-controlled study of donepezil in patients with mild to moderate AD. Neurology. 2001; 57: 489-95.

156. Rosler M, Anand R, Cicin-Sain A, et al. Efficacy and safety of rivastigmine in patients with Alzheimer's disease: international randomised controlled trial. BMJ. 1999; 318: 633-8.

157. Knapp MJ, Knopman DS, Solomon PR, et al. A 30-week randomized controlled trial of high-dose tacrine in patients with Alzheimer's disease. The Tacrine Study Group. JAMA. 1994; 271: 985-91.

158. Corey-Bloom J, Anand R, Veach J. A randomized trial evaluating the efficacy and safety of ENA 713 (rivastigmine tartrate), a new acetylcholinesterase inhibitor, in patients with mild to moderately severe Alzheimer's disease. Int J Geriatr Psychopharmacol. 1998. 1: $55-65$.

159. Wilkinson D, Murray J. Galantamine: a randomized, double-blind, dose comparison in patients with Alzheimer's disease. Int $\mathbf{J}$ Geriatr Psychiatry. 2001; 16: 852-7.

160. Feldman H, Gauthier S, Hecker J, et al. Efficacy of donepezil on maintenance of activities of daily living in patients with moderate-to-severe Alzheimer's disease and the effect on caregiving burden. J Am Geriatr Soc. 2003; 51: 737-44.

161. Bullock R. The needs of the caregiver in the long-term treatment of Alzheimer's disease. Alzheimer Dis Assoc Disord. 2004; 18: S17-23.

162. Markowitz JS, Guterman EM, Sadik K, et al. Health-related quality of life for caregivers of patients with Alzheimer disease. Alzheimer Dis Assoc Disord. 2003; 17: 209-14.

163. Busschbach JJ, Brouwer WB, van der Donk A, et al. An outline for a cost-effectiveness analysis of a drug for patients with Alzheimer's disease. Pharmacoeconomic.s 1998; 13: 21-34.

164. Fillit HM, Gutterman EM, Brooks RL. Impact of donepezil on caregiving burden for patients with Alzheimer's disease. Int Psychogeriatr. 2000; 12: 389-401.

165. Consensus recommendations for the postmortem diagnosis of Alzheimer's disease. The National Institute on Aging, and Reagan Institute Working Group on Diagnostic Criteria for the Neuropathological Assessment of Alzheimer's Disease. Neurobiol Aging. 1997; 18: S1-2.

166. Burger K, Zinkowski R, Teipel SJ, et al. Differential diagnosis of Alzheimer's disease with CSF tau protein phosphorylated at threonine 231. Arch Neurol. 2002; 59(8): 1267-72.

167. de Leon MJ, Segal CY, Tarshish CY, et al. Longitudinal CSF tau load increases in mild cognitive impairment. Neurosci Lett. 2002; 333: 183-6.

168. Grundman M, Sencakova D, Jack CRJ, et al. Brain MRI hippocampal volume and prediction of clinical status in a mild cognitive impairment trial. J Mol Neurosci. 2002; 19: 23-7.

169. Shoghi-Jadid K, Small GW, Agdeppa ED, et al. Localization of neurofibrillary tangles and beta-amyloid plaques in the brains of living patients with Alzheimer disease. Am J Geriatr Psychiatry. 2002; 10: 24-35. 
170. Klunk WE, Engler H, Nordberg A, et al. Imaging brain amyloid in Alzheimer's disease with Pittsburgh Compound-B. Ann Neurol. 2004; 55: 306-19.

171. U.S. Department of Health and Human Services, Food and Drug Administration, Center for Drug Evaluation and Research (CDER), Center for Biologics Evaluation and Research (CBER), Center for Devices and Radiological Health (CDRH). Guidance for Industry: Pharmacogenomic Data Submission. Available from: http://www.fda.gov/cder/guidance/6400fnl.pdf

172. Feldman H, Scheltens P, Scarpini E, et al. Behavioral symptoms in mild cognitive impairment. Neurology. 2004; 62: 1199-201.

173. Thal LJ, Ferris SH, Kirby L, et al. A randomized, double-blind, study of rofecoxib in patients with mild cognitive impairment. Neuropsychopharmacology. 2005; [Epub ahead of print].

174. Ritchie K, Artero S, Touchon J. Classification criteria for mild cognitive impairment: a population-based validation study. Neurology. 2001; 56: 37-42.

175. Erkinjuntti T, Roman G, Gauthier S, Feldman H, Rockwood K. Emerging therapies for vascular dementia and vascular cognitive impairment. Stroke. 2004; 35: 1010-7.

176. Rockwood K, Howard K, MacKnight C, Darvesh S. Spectrum of disease in vascular cognitive impairment. Neuroepidemiology. 1999; 18: 248-54.

177. Erkinjuntti T, Inzitari D, Pantoni L, et al. Research criteria for subcortical vascular dementia in clinical trials. J Neural Transm. Suppl 2000; 59: 23-30.

178. Roman GC, Erkinjuntti T, Wallin A, Pantoni L, Chui HC. Subcortical ischaemic vascular dementia. Lancet Neurol. 2002; 1: 426-36.

179. Erkinjuntti T, Kurz A, Gauthier SG, Bullock R, Lilienfeld S, Damaraju CV. Efficacy of galantamine in probable vascular dementia and Alzheimer's disease combined with cerebrovascular disease: a randomised trial. Lancet. 2002; 359: 1283-90.

180. Orgogozo JM, Rigaud AS, Stoffler A, Mobius HJ, Forette F. Efficacy and safety of memantine in patients with mild to moderate vascular dementia: a randomized, placebo-controlled trial (MMM 300). Stroke. 2002; 33: 1834-9.

181. McKeith I, del Ser T, Spano P, et al. Efficacy of rivastigmine in dementia with Lewy bodies: a randomised, double-blind, placebo-controlled international study. Lancet. 2000; 356: 2031-6.

182. Emre M, Aarsland D, Albanese A, et al. Rivastigmine for dementia associated with Parkinson's disease. N Engl J Med. 2004; 351: 2509-18.

183. The French Clozapine Parkinson Study Group. Clozapine in DrugInduced Psychosis in Parkinson's disease. Lancet. 1999; 353: 2041-2.

184. The Parkinson Study Group. Low-dose clozapine for the treatment of drug-induced psychosis in Parkinson's disease. N Engl J Med. 1999; 340: 757-63.

185. Fernandez HH, Trieschmann ME, Burke MA, Friedman JH. Quetiapine for psychosis in Parkinson's disease versus dementia with Lewy bodies. J Clin Psychiatry. 2002; 63: 513-5.

186. Fernandez HH, Trieschmann ME, Burke MA, Jacques C, Friedman JH. Long-term outcome of quetiapine use for psychosis among Parkinsonian patients. Mov Disord. 2003; 18: 510-4.

187. Kertesz A, Munoz DG, Hillis A. Preferred terminology. Ann Neurol. 2003; 54 Suppl. 5: S3-6.

188. Ratnavelli E, Brayne C, Dawson RGN, Hodges JR. The prevalence of frontotemporal dementia. Neurology. 2002; 58: 1615-21.

189. Ikeda M, Ishikawa T, Tanabe H. Epidemiology of frontotemporal lobar degeneration. Dement Geriatr Cogn Disord. 2004; 17: 265-8.

190. Gustafson L, Brun A. Frontal lobe degeneration of non-Alzheimer type and its relation to other frontotemporal dementias and Alzheimer's disease. In: Kertesz A, Munoz DG, editors. Pick's Disease and Pick Complex. Toronto: Wiley-Liss, 1998. p.33-46.

191. Sparks D L, Markesbery W R. Altered serotonergic and cholinergic synaptic markers in Pick's disease. Arch Neurol. 1991; 48: 796-9.

192. Sjögren M, Minthon L, Passant U, Blennow K, Wallin A. Decreased monoamine metabolites in frontotemporal dementia and Alzheimer's disease. Neurobiol Aging. 1998; 19(379): 384.
193. Proctor AW, Qurne M, Francis PT. Neurochemical features of Frontotemporal dementia. Dement Geriatr Cogn Disord. 1999; 10 Suppl 1: S80-4.

194. Lebert F, Pasquier F. Trazodone in the treatment of behavior in frontotemporal dementia. Hum Psychopharmacol Clin Exp. 1999; 14: 279-81.

195. Lebert F, Stekke W, Hasenbroekx C, Pasquier F. Frontotemporal dementia: a randomized, controlled trial with Trazodone. Dement Geriatr Cogn Disord. 2004; 17: 355-9.

196. Sahakian BJ, Coull BL, Hodges JR. Selective enhancement of executive function by idazoxan in a patient with dementia of the frontal lobe type. J Neurol Neurosurg Psychiatry. 1994; 57: 120-1.

197. Anderson IM, Scott K, Harborne G. Serotonin and depression in frontal lobe dementia. Am J Psychiatry. 1995; 152: 645.

198. Swartz JR, Miller BL, Lesser IM, Darby AL. Frontotemporal dementia: treatment response to serotonin selective reuptake inhibitors. J Clin Psychiatry. 1997; 58: 212-6.

199. Chow TW. Goals in symptomatic pharmacologic management of frontotemporal lobar degeneration. Am J Alzheimers Dis Other Demen. 2002; 17: 267-72.

200. Ikeda M, Shigenobu K, Fukuhara R, et al. Efficacy of fluvoxamine as a treatment for behavioral symptoms in frontotemporal lobar degeneration patients. Dement Geriatr Cogn Disord. 2004; 17: 117-21.

201. Moretti R, Torre P, Antonello RM, Cazzato G, Bava A. Frontotemporal dementia: paroxetine as a possible treatment of behavior symptoms. A randomized, controlled, open 14-month study. Eur Neurol. 2003; 49: 13-9.

202. Moretti R, Torre P, Antonello RM, Cazzato G, Bava A. Effects of selegiline on fronto-temporal dementia: a neuropsychological evaluation. Int J Geriatr Psychiatry. 2002; 17: 391-2.

203. Adler G, Teufel M, Drach LM. Pharmacological treatment of frontotemporal dementia: treatment response to the MAO-A inhibitor moclobemide. Int J Geriatr Psychiatry. 2003; 18: 653-5.

204. Goforth HW, Konopka L, Primeau M, et al. Quantitative electroencephalography in frontotemporal dementia with methylphenidate response: a case study. Clin EEG Neurosci. 2004; 35: 108-11

205. Gregory C, Lough S, Stone V, et al. Theory of mind in patients with frontal variant frontotemporal dementia and Alzheimer's disease: theoretical and practical implications. Brain. 2002; 125 pt. 4: $752-64$.

206. Freedman M, Black S, Ebert P, Binns M. Orbitofrontal function, object alternation, and perseveration. Cereb Cortex. 1998; 8: 18-27.

207. Freedman M, Binns MA, Black SE, et al. Object Alternation: a cognitive and diagnostic measure of orbitofrontal function in frontotemporal dementia. Neurology. 2003; Suppl 1: A264.

208. Royall D, Mahurin RK, Gray KF. Bedside assessment of executive cognitive impairment: the executive interview. J Am Geriatr Soc. 1992; 40: 1221-6.

209. Dubois B, Slachevsky A, Litvan I, Pillon B. The FAB: a frontal assessment battery at bedside. Neurology. 2000; 55: 1621-6.

210. Mathuranath PS, Nestor PJ, Berrios GE, Rakowicz W, Hodges JR. A brief cognitive test battery to differentiate Alzheimer's disease and frontotemporal dementia. Neurology. 2000; 55: 1613-20.

211. Heaton RK. Wisconsin Card Sorting Test Manual. Florida: Psychological Assessment Resources Inc., 1981.

212. Freedman M, Leach L, Kaplan E, et al. Clock drawing: a neuropsychological analysis. New York: Oxford University Press.

213. Kertesz A, Davidson W, Fox H. Frontal behavioral inventory: diagnostic criteria for frontal lobe dementia. Can J Neurol Sci. 1997; 24: 29-36.

214. Kertesz A, Nadkarni N, Davidson W, Thomas AW. The frontal behavioral inventory in the differential diagnosis of frontotemporal dementia. J Int Neuropsychol Soc. 2004; 6(460): 468.

215. Kertesz A, Davidson W, McCabe P, Munoz D. Behavioral quantitation is more sensitive than cognitive testing in frontotemporal dementia. Alzheimer Dis Assoc Disord. 2003; 17: 223-9. 
216. Grace J, Stout JC, Malloy PF. Assessing frontal lobe behavioral syndromes with The Frontal Lobe Personality Scale. Assessment. 1999; 6: 269-84.

217. Stout JC, Ready RE, Grace J, Malloy PF, Paulsen JS. Factor analysis of the frontal systems behavior scale (FrSBe). Assessment. 2003; 10: 79-85.

218. Hodes RJ, Testimony, United States Department of Health and Human Services. Available from: http://www.hhs.gov/asl/ testify/t040511c.html

219. Christen Y. Ginkgo biloba and neurodegenerative disorders. Front Biosci. 2004; 9: 3091-104.

220. Le Bars PL, Katz MM, Berman N, et al. A placebo-controlled, double-blind, randomized trial of an extract of Ginkgo biloba for dementia. North American EGb Study Group. JAMA. 1997; 278: 1327-32.

221. Blesch A, Tuszynski MH. Gene therapy and cell transplantation for Alzheimer's disease and spinal cord injury. Yonsei Med J. 2004; 45 Suppl: S28-31.

222. May PC. Current progress on new therapies for Alzheimer's disease. Drug Discov Today. 2001; 6: 459-62.

223. Schenk D, Hagen M, Seubert P. Current progress in beta-amyloid immunotherapy. Curr Opin Immunol. 2004; 16(5): 599-606.

224. Chou KC. Insights from modeling the tertiary structure of human BACE2. J Proteome Res. 2004; 3: 1069-72.

225. Ritchie CW, Bush AI, Mackinnon A, et al. Metal-protein attenuation with iodochlorhydroxyquin (clioquinol) targeting Abeta amyloid deposition and toxicity in Alzheimer disease: a pilot phase 2 clinical trial. Arch Neurol. 2003; 60: 1685-91.

226. Di Vaira M, Bazzicalupi C, Orioli P, et al. Clioquinol, a drug for Alzheimer's disease specifically interfering with brain metal metabolism: structural characterization of its zinc (II) and copper (II) complexes. Inorg Chem. 2004; 43: 3795-7.

227. Gervais F, Chalifour R, Garceau D, et al. Glycosaminoglycan mimetics: a therapeutic approach to cerebral amyloid angiopathy. Amyloid. 2001; 8 Suppl 1: S28-35.

228. Ritchie CW, Bush AI, Masters CL. Metal-protein attenuating compounds and Alzheimer's disease. Expert Opin Investig Drugs. 2004; 13: 1585-92.

229. Watson GS, Craft S. The role of insulin resistance in the pathogenesis of Alzheimer's disease: implications for treatment. CNS Drugs. 2003; 17: 27-45.

\section{CONTRIBUTORS}

Dr. Peter A. B. Bailey: Department of Medicine, Dalhousie University; Saint John Regional Hospital Facility and St Joseph's Hospital.

Dr. Lynn Beattie: Division of Geriatric Medicine, Department of Medicine, University of British Columbia and UBC Hospital.

Dr. Sandra E. Black: Division of Neurology, Department of Medicine, University of Toronto; Division of Neurology, Sunnybrook \& Women's College Health Sciences Centre.

Dr. Rémi Bouchard: Division of Neurology, Department of Medicine, Université Laval; Memory Clinic and AD Research Unit, Centre Hospitalier Affilié de Québec-Hôpital Enfant-Jesus and Hôpital Laval.

Dr. Richard Camicioli: Division of Neurology, Department of Medicine, University of Alberta; Glenrose Rehabilitation Hospital.

Dr. William B. Dalziel: Division of Geriatric Medicine, Department of Medicine, University of Ottawa; Ottawa Hospital, Civic Campus.

Dr. Steven T. DeKosky: Department of Neurology, Alzheimer's Disease Research Center, University of Pittsburgh; University of Pittsburgh Medical Center.

Dr. John D. Fisk: Department of Psychiatry, Dalhousie University Medical School; Queen Elizabeth II Health Sciences Centre.
Dr. Nathan Herrmann: Division of Geriatric Psychiatry, Department of Psychiatry, University of Toronto; Department of Psychiatry, Sunnybrook and Women's College Health Sciences Centre.

Dr. David B. Hogan: Division of Geriatric Medicine, Department of Medicine, University of Calgary; Foothills Medical Centre.

Dr. Andrew Kirk: Division of Neurology, Department of Medicine, University of Saskatchewan; Royal University Hospital.

Dr. Fadi Massoud: Division of Geriatric Medicine, Department of Medicine, Université de Montréal; Centre Hospitalier de l'Université de Montréal Hôpital Notre-Dame.

Dr. I. Gary Naglie: Division of Geriatric Medicine, Department of Medicine, University of Toronto; Toronto Rehabilitation Institute-University Centre, University Health Network, Toronto General Hospital Site.

Dr. Judes Poirier: Faculty of Medicine, McGill Centre for Studies in Aging, McGill University.

Dr. François Primeau: Department of Psychiatry, Faculty of Medicine, Université Laval; Hôtel-Dieu de Lévis.

Dr. Kiran Rabheru: Department of Psychiatry, University of Western Ontario; Regional Mental Health Care, London, Ontario.

Dr. Kenneth J. Rockwood: Department of Medicine (Geriatric Medicine and Neurology), Dalhousie University, Division of Geriatric Medicine; Queen Elizabeth II Health Sciences Centre. Dr. David Streiner: Department of Psychiatry, University of Toronto, and Department of Clinical Epidemiology and Biostatistics, McMaster University; Baycrest Centre.

Dr. Lilian U. Thorpe: Department of Psychiatry, University of Saskatchewan; Saskatoon City Hospital.

Dr. Lisa Kelly: Canadian Therapeutics Product Directorate.

Dr. Maribeth Lazzaro: Canadian Therapeutics Product Directorate.

Dr. Catherine Petersen: Canadian Therapeutics Product Directorate.

Dr. Jack Diamond: Scientific Director, Alzheimer Society of Canada.

Ms. Ilona Horgen: Director of Support Services and Education, Alzheimer Society of Canada.

Mr. Steve Rudin: Executive Director, Alzheimer Society of Canada.

\section{ACKNOWLEDGEMENTS}

The 2nd Canadian Conference on Guidelines for the Development of Antidementia Therapies was supported by a workshop grant of the Canadian Institutes of Health Research Institute on Aging, by a workshop grant from the Canadian Consortium of Clinical Cognitive Research Centers (C5R), and by an unrestricted grant in aid from the following pharmaceutical companies - AstraZeneca Canada Inc., Aventis Pharma Inc., Boehringer Ingelheim Canada Ltd., GlaxoSmithKline Inc., Janssen-Ortho Inc., Lundbeck Canada Inc., Myriad Genetics, Inc., Novartis Pharmaceuticals Inc., ONO Pharma USA Inc., Pfizer Canada Inc., Sanofi-Synthelabo Canada Inc., Institut de Recherches Internationales Servier. The conference gratefully acknowledges this sponsorship. 
The Conference also wishes to recognize the seminal contribution of Dr. Erich Mohr to the initial Conference and Guidelines paper and for his insights that are still evident within the current conference and this paper.

The contribution to the discussions of both the Therapeutic Product Directorate of Health Canada and the Alzheimer Society of Canada are gratefully acknowledged as well as the contributions of the external advisers to the conference Dr. Steven DeKosky and Dr. Jean Marc Orgogozo.

The Conference gratefully acknowledges the role of MedPlan in assisting in the planning, logistics and organization of this Conference and in assisting in the editing and formatting of this publication. The contribution of Jacob Grand is acknowledged for his assistance in the organization of the reference section of this paper.

During the preparation of this conference:

Dr. Howard Feldman held grant funding from the Alzheimer Society of Canada, and received support from the Brain Research Center UBC, and Vancouver Coastal Health Research Institute (VCHRI).

Within the past 2 years Dr. Feldman had Grant/Research support from Pfizer, Eisai, Janssen, Lilly, Astra Zeneca, Sanofi Synthelabo and GlaxoSmithKline; was a Consultant for: Astra Zeneca, Pfizer, Eisai, Novartis, Janssen, Servier, Sanofi
Synthelabo, GlaxoSmithKline, Myriad, Targacept, Lundbeck and Axonyx; was on the Speakers' Bureau or CME programs for: Pfizer, Eisai, Janssen, Novartis and Forest.

Dr. Serge Gauthier held a Research Chair position from the CIHR (Canadian Institutes for Health Research) - Rx\&D Program.

Dr. Howard Chertkow was supported by operating grants from the CIHR (Canadian Institutes for Health Research), and was a "chercheur national" of the FRSQ (Fonds de la Recherche en Santé du Québec). This research was carried out at the Sir Mortimer B. Davis - Jewish General Hospital Memory Clinic.

Dr. Morris Freedman held a research grant from the Canadian Institutes of Health Research and was supported by the Saul A. Silverman Family Foundation, Toronto, Ontario, Canada, as part of a Canada International Scientific Exchange Program (CISEPO) project.

Dr. Chris McKnight was supported by a new investigator award from the Canadian Institutes of Health Research. 